\title{
Characterization of cohesive model and bridging laws in mode I and II fracture in nanocomposite laminates
}

\author{
P. Ghabezi ${ }^{1}$ and M. Farahani ${ }^{1 *}$ \\ ${ }^{1}$ School of Mechanical Engineering, College of Engineering, \\ University of Tehran, Tehran, Iran. \\ Phone: +982188353893; Fax: +982188013029 \\ *E-mail: mrfarahani@ut.ac.ir
}

\begin{abstract}
The cohesive model and traction-separation curves have brought a considerable possibility for researchers and fracture engineers to assess and simulate failure in composite laminates. Reliable determination of the traction-separation laws is very pivotal to the success of this approach in finite element methods. The objective of this paper is assessment of nanoparticles effect on bridging laws, cohesive mechanism and traction-separation parameters of nanocomposites mode I and II fracture. To do this analyzing of the experimental data from double cantilever beam, and end notched flexure tests including construction of the R-curves (energy release rate versus crack length), reconstruction of these curves in terms of the pre-crack tip opening and sliding displacement, and calculation of the corresponding bridging and traction-separation laws through the J-integral approach were carried out. For the calculation of the energy release rate in Mode I, three corresponding data reduction schemes namely Corrected Beam Theory, Experimental Compliance Method and Modified Compliance Calibration are utilized, while Compliance Calibration Method, Corrected Beam Theory and Compliance-Based Beam and II fracture are applied for that of mode II. The main concern of this research is introduction of critical parameters of two modified models to simulate mode I and II fracture. Adding $0.43 \mathrm{wt} \%$ nanoparticles to composite DCB samples leads to increase of $116 \%, 68 \%$ and $70 \%$ in $\mathrm{G}_{\mathrm{I}, 0}$ calculated by CBT, ECM and MCC respectively, and a $72 \%$ increase in $\mathrm{G}_{\mathrm{I}, \mathrm{ss}}$ is measured by CBT, while this value for ECM and MCC is $110 \%$ and $48 \%$. Adding $0.2 \mathrm{wt} \%$ nanoparticles to the composite samples results in $86 \%(50 \mathrm{MPa})$ increase in critical stress in mode II fracture calculated by method CBBM. This method presented the lowest value for critical displacement, fluctuated between $0.08-.11 \mathrm{~mm}$ in mode II.
\end{abstract}

Keywords: Cohesive model; Bridging law; Nanocomposite; Traction-separation.

\section{INTRODUCTION}

The most applicable method used for the determination of interlayer fracture resistance of composite laminates is the measurement of strain energy release rate, G (ERR-G). Strain energy release rate (SERR) is constant when the crack growth resistance is independent of the crack length $(\alpha)$. In this case, the SERR is equal to the failure toughness, $\mathrm{G}_{\mathrm{I}, 0}$ or $\mathrm{G}_{\mathrm{II}, 0}$ in 
Mode I or Mode II, respectively. To determine $\mathrm{G}_{\mathrm{I}, 0}$ under pure opening load (mode $\mathrm{I}$ ), the double cantilever beam (DCB) test has been considered as a standard method (ISO 15024:2001 [1];ASTM D5528-01 [2]). End Notched Flexure (ENF) [3], End Loaded Split (ELS) and Four Point ENF (4ENF) tests are the most popular tests adopted in the literature to calculate $\mathrm{G}_{\mathrm{II}, 0}$ in mode II fracture. Bensattalah et al. [4] used a nonlocal elasticity theory and the Euler-Bernoulli and Timoshenko beam theories, the free vibration of single-walled carbon nanotubes embedded in an elastic medium to investigate the thermal and chirality effects. The mechanical properties of carbon nanotubes and polymer matrix are treated as functions of temperature, and an analytical solution is derived using the governing equations of the nonlocal Euler-Bernoulli and Timoshenko beam models. The results obtained show that the frequency ratio is significantly affected by the chirality of the singlewalled carbon nanotubes. $\mathrm{Xu}$ et al. [5] Used an improved multilayered plate model to investigate the influence of surface and interface energies on the bending behaviour of laminated into the Kirchhoff plate theory. Governing equations taking into account the geometrical nonlinearity are obtained to study the influences of surface/interface energies. Based on the Navier and Ritz methods, closed-form solutions for both simply supported and clamped nanoplates are obtained. Numerical results for single- and multilayered nanoplates indicate that the interface effect can noticeably change the elastic behaviour of laminated plates on the nanometer scale. In addition, the flakiness ratio, external load, and number of layers also affect the surface/interface effects at large deformations. This study will be useful for the design and examination of nanoplates and nanoscale devices, especially multilayered plates at large deformations. Chafidz et al. [6] investigated effects of different loadings of date palm fibers (DPE) on the morphological, thermal and melt rheological properties of the composites made from high density Polyethylene (HDPE) and natural date palm fibers. They used morphological investigation to show that the fibers were evenly dispersed in HDPE matrix at all DPF loadings. Yasser Zare [7] studied the roles of the dispersion/accumulation of nanoparticles and interphase condition on the tensile modulus and strength of polymer Nano composites by original or developed models and equations. The main focus is performed on the concentration, size and modulus of nanoparticles as well as the thickness, modulus and strength of interphase. Xin Liang et al. [8] employed atomic layer deposition (ALD) to deposit thin oxide layers on Multi-wall carbon nanotubes. These core-shell structures were then used to create Nano composites by using a polymer derived ceramic (PDC) to produce the matrix. Variations in both the initial MWCNT structure and the oxide layers led to substantial differences in fiber-pullout behavior. Chaeichian et al. [9] synthesized a hybrid ternary system of thermoplastic/clay/thermoset to produce a tougher unsaturated polyester without reducing the glass transition temperature or the elastic modulus. Mixed mode fracture resistance of epoxy-based Nano composites reinforced with carbon nanoparticles of three different shapes is studied by Shadlou et al. [10]. Vanpariya et al. [11] experimentally have derived the traction separation curve also known as cohesive law for copper (UNS C11040) under plane stress condition. Rajan et al. [12] used double cantilever experiments at three different loading rates $(0.03 \mathrm{~mm} / \mathrm{min}, 0.3 \mathrm{~mm} / \mathrm{min}$ and $3 \mathrm{~mm} / \mathrm{min})$ to derive tractionseparation relationship for polymer-modified bitumen under Mode I loading. Loaddisplacement measurements were synchronized with speckle image acquisition and the data analyzed to determine J-integral, cohesive zone end opening displacement, and the crack opening displacement as a function of crack extension. Park et al. [13] showed that the 
traction-separation relationship in Abaqus can lead to non-physical responses because of a pathological positive tangent stiffness under softening condition. This is reflected in cohesive tractions that increase and decrease repeatedly while the cohesive separation monotonically increases.

It is evident from the previous research works carried out on fracture mechanics using cohesive models and traction-separation curves that accurate experimental parameters such as critical stress and displacement in mode I and II fracture play a significant role in simulation of crack propagation in composite parts under normal and shear stress. Lack of experimental work on derivation of cohesive model parameters and effect of nano particles on the critical contributing factors was the main incentive of the present work. In one hand, the novelty of present study includes an experimental study on bridging and cohesive mechanism of mode I and II fracture growth in laminated nanocomposites within the LEFM and damage mechanics frameworks in presence on various weight fractions of nanoalumina particles. On the other hand, the main concern of this research is introduction of critical parameters of two modified models to simulate fracture behavior of composite samples under mode I and II fracture. Polymer-based nanocomposites samples with glass fibers and alumina nanoparticle has been fabricated and underwent DCB and ENF tests according to ASTM standards. Another problem of this study was comparison of three different types of traction-separation laws and the effect of adding nanoparticles on their main parameters in mode I and II. The obtained bridging laws and cohesive mechanism (traction-separation laws) for each data reduction method and different nanoparticles wt\% can be used in the finite element methods for numerical simulation of DCB and ENF tests and evaluation of mode I and II nanocomposites fracture.

\section{MATERIALS AND TESTS}

In this study, vacuum assisted resin transfer molding (VARTM) was used to fabricate experimental specimens $[14,15]$. The preform was comprised of six glass fiber layers $(200 \mathrm{~g} ; 30 \times 20 \mathrm{~cm})$, a layer of Dacron fabric strips, and a distribution layer. The selected polymer resin was comprised of two components mixed with the weight ratio of $12 \%$ : (1) epoxy-based EPH 1012, and (2) EPH 112 as hardener $(\mathrm{E}=2.73 \mathrm{GPa}, \sigma \mathrm{Y}=74.62 \mathrm{MPa})$. In this work, Alpha -alumina nanoparticles with 99\% purity, average nanoparticle size (ASP) of $\sim 80 \mathrm{~nm}$, and specific surface area (SSA) of smaller than $10 \mathrm{~m} 2 / \mathrm{g}$ (Notrino Company) is used [16]. After curing and preparing nanocomposite samples with different amounts of nanoparticle, three cuts $\left(25^{*} 250 \mathrm{~mm}\right)$ of each sample were made using a water jet cutter according to ASTM D3039 standard. To obtain mechanical specifications, tensile test was applied on different specimens (Table 1). Tests were conducted by a hydraulic machine (WDW-300E; load accuracy: 0.001 mm; load cell: $15 \mathrm{kN}$; UTM-300E controlling system). 
Table 1. Mechanical Properties of Nano-composites samples.

\begin{tabular}{lcccc}
\hline Sample & $\begin{array}{c}\text { Nano } \\
\text { Wt \% }\end{array}$ & $\begin{array}{c}\text { Tensile Strength } \\
\text { (MPa) }\end{array}$ & $\begin{array}{c}\text { Ultimate Strain } \\
\text { \% }\end{array}$ & $\begin{array}{c}\text { Young Modulus } \\
\text { (GPa) }\end{array}$ \\
\hline Code- 0 & 0 & 279.7 & 0.03 & 9.48 \\
Code- 0.2 & 0.2 & 289.4 & 0.031 & 9.33 \\
Code- 0.43 & 0.43 & 312.7 & 0.03 & 10.42 \\
Code-1 & 1 & 308.9 & 0.033 & 9.36 \\
Code- 2.1 & 2.1 & 301.2 & 0.027 & 11.36 \\
Code- 4.1 & 4.1 & 297 & 0.027 & 11 \\
\hline
\end{tabular}

It is apparent from the results presented in Table 1 that the maximum values of the ultimate stress $(312.7 \mathrm{MPa})$, failure strain $(0.033 \%)$, and Young modulus $(11.36 \mathrm{GPa})$ belong to the samples with the weight ratios of $0.43,1$, and $2.1 \%$, respectively. Alumina nanoparticles can effectively improve the mechanical performances of glass/epoxy composites. In the following, the composite sample fabrication stages using VARTM process are described $[17,18]$ : First, Alpha-alumina nano-powder was heated in an oven at $80^{\circ} \mathrm{C}$ for 150 minutes and $120^{\circ} \mathrm{C}$ for 150 minutes to ensure complete moisture loss. To fabricate nano-composite samples, nanoparticles were first mixed with the hardener (due to lower viscosity of the hardener) with $0.2,0.43,2.1$, and $4.1 \mathrm{wt} \%$ to the total weight of the resin, using a magnetic stirrer for 20 minutes and rotation rate of 1800 RPM. Then, the obtained mixture was sonicated for 15 minutes, using the Hielscher ultrasonic device UP400S set to Cycle 0.8 and Amplitude $80 \mu \mathrm{m}$. The mixture was placed in a laboratory container and mechanically stirred with the resin for 5 minutes at the room temperature. The glass die was cleaned using detergents like acetone. The separating layer in the die was created with RENLEASE QV 5110.The preform was comprised of 6 layers of glass fibers $(200 \mathrm{~g} ; 30 \times 20 \mathrm{~cm})$, a layer of Dacron fabric strips, and a distribution layer. By preparing and connecting the hydraulic system, sealant, and vacuum bags, the die was prepared for injection of the resin. The system was connected to a vacuum pump and the resin was injected into the preform and die under the vacuum pressure of -0.8 bar $[18,19]$. Figure 1 shows different components of VARTM fabrication process.

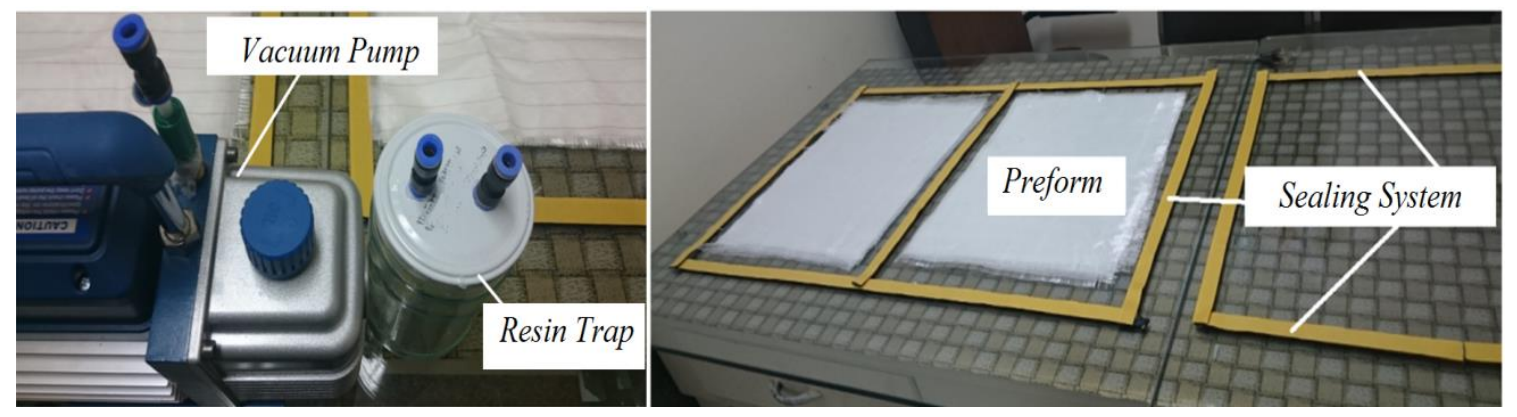

Figure 1. VARTM Process components. 
Figure 2 presents scanning electron microscope (SEM) images of the sample with 1wt\%, showing good nanoparticle distribution in the matrix.
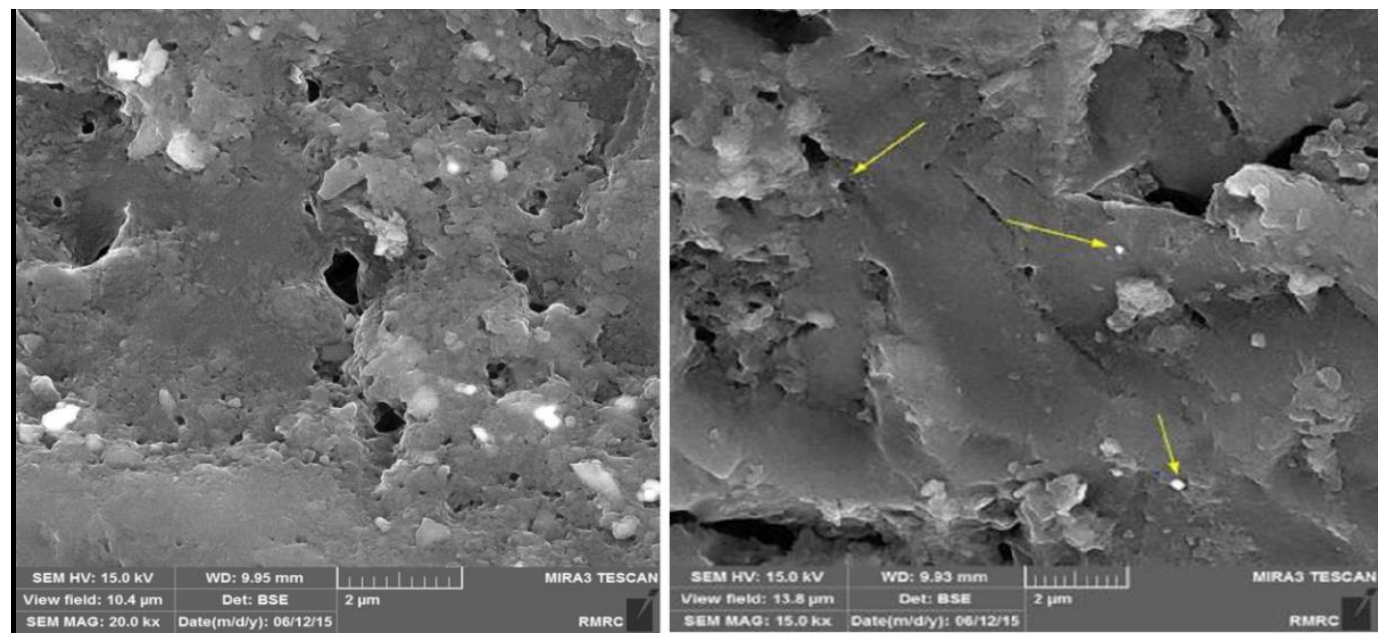

Figure 2. SEM images for distribution of nanoparticles into epoxy matrix.

The geometry and dimensions of DCB and ENF samples are presented in Figure 3. The actual thickness and width of samples were equal to $2 \mathrm{~h}=4.5 \pm 0.1$ and $\mathrm{b}=20 \mathrm{~cm}$, respectively. The length of pre-crack $\alpha_{0}$ (the length of initial delamination) was $50 \mathrm{~mm}$ (according to ASTM D5528-01, 2007) for DCB and 35mm for ENF specimens, respectively [20]. To prevent the application of moment on composite samples during DCB test, adhesive was used to bond two steel hinges to the edge of the pre-cracked DCB samples [21, 22, 23$]$.
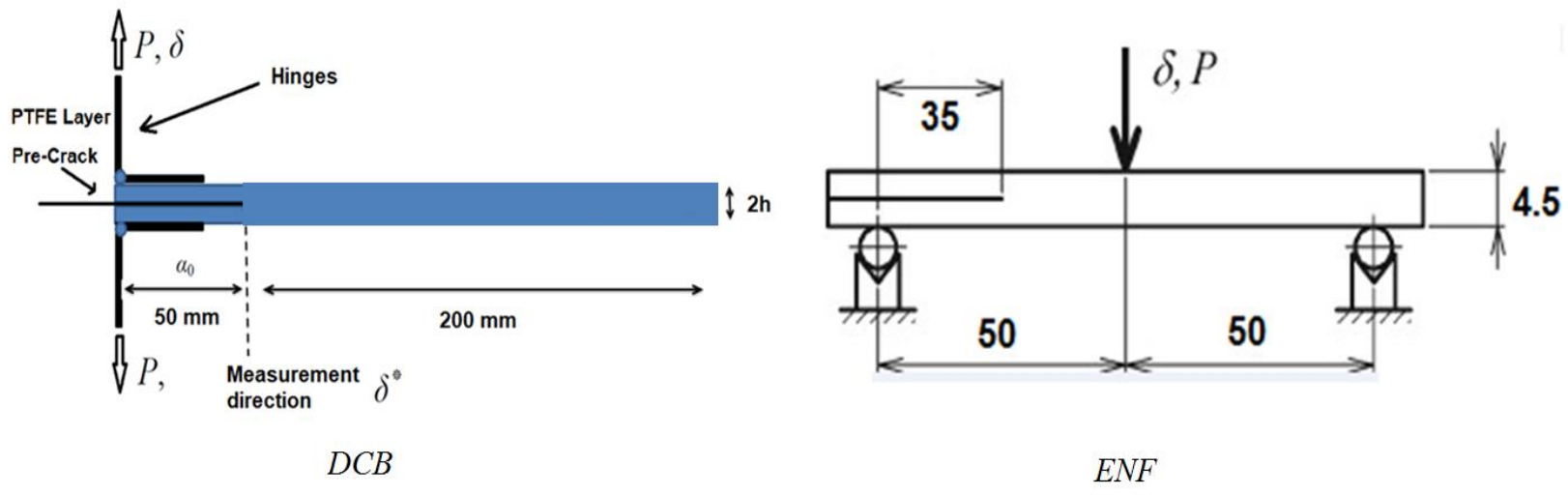

Figure 3. DCB and ENF test dimensions [1, 2]. 

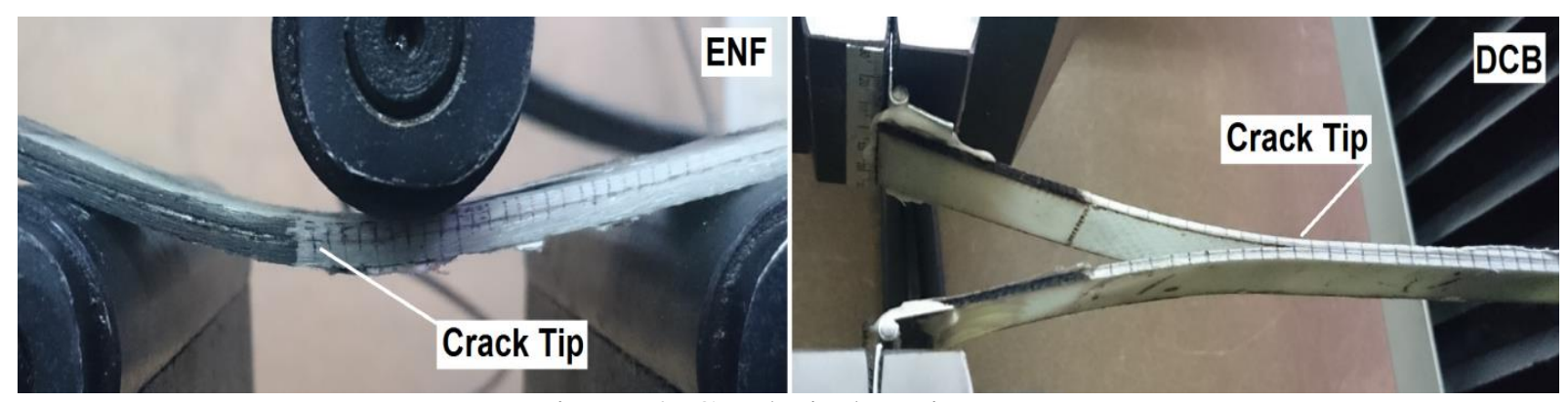

Figure 4. Crack tip location.

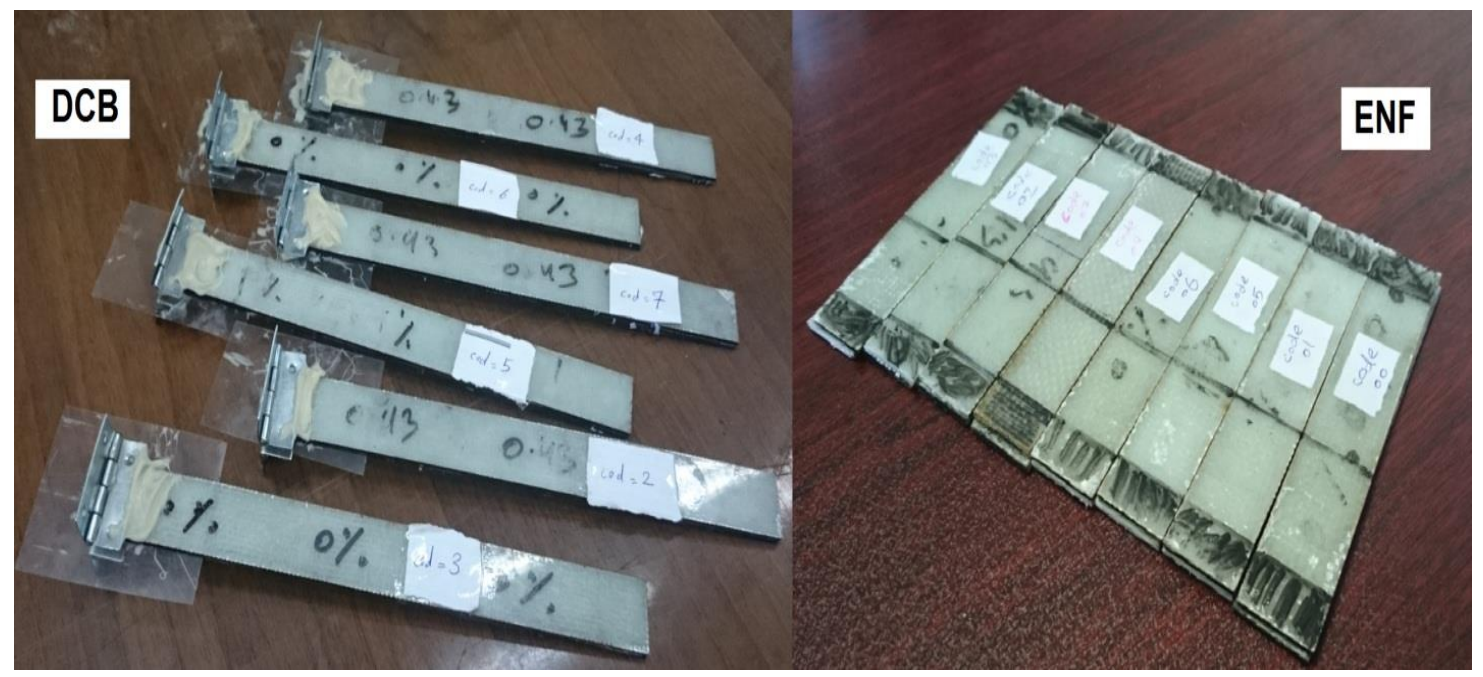

Figure 5. DCB and ENF samples.

In DCB samples, the crack length $(\alpha)$ is defined as the distance between the loading line and the crack tip. Crack development monitoring was done visually along the crack, using a high-resolution camera. To help measure the crack length, vertical thin lines were marked on the side edges of the samples with $5 \mathrm{~mm}$ (in DCB test) and $2 \mathrm{~mm}$ (in ENF test) spacing $(\Delta \alpha$; Figure 4). Tensile test was applied on DCB samples with the rate of $2 \mathrm{~mm} / \mathrm{min}$. During each test, the force-displacement curve $(\mathrm{P}-\delta)$ and relative displacement of pre-crack tip $\left(\delta^{*}\right)$ were recorded as a function of time. Figure 5 shows some DCB and ENF test samples. A code (Code-X), in which $\mathrm{X}$ represents nanoparticle content of composite (\%), is introduced to nominate nanocomposite samples.

\section{DATA REDUCTION METHODS}

Data reduction methods were applied on Mode I displacement data to be used in J-integral method and for the extraction of bridging principles and energy release rate. In this study, three different data reduction methods were used for the calculation of mode I ERR: Corrected Beam Theory (CBT), Experimental Compliance Method (ECM) and Modified Compliance Calibration (MCC). The ECM, CBT, and MCC methods are proposed by 
ASTM D5528-01 standard. Table 2 explains the parameters required in data reduction methods for mode I fracture.

Table 2. Parameters of data reduction methods for mode I [21].

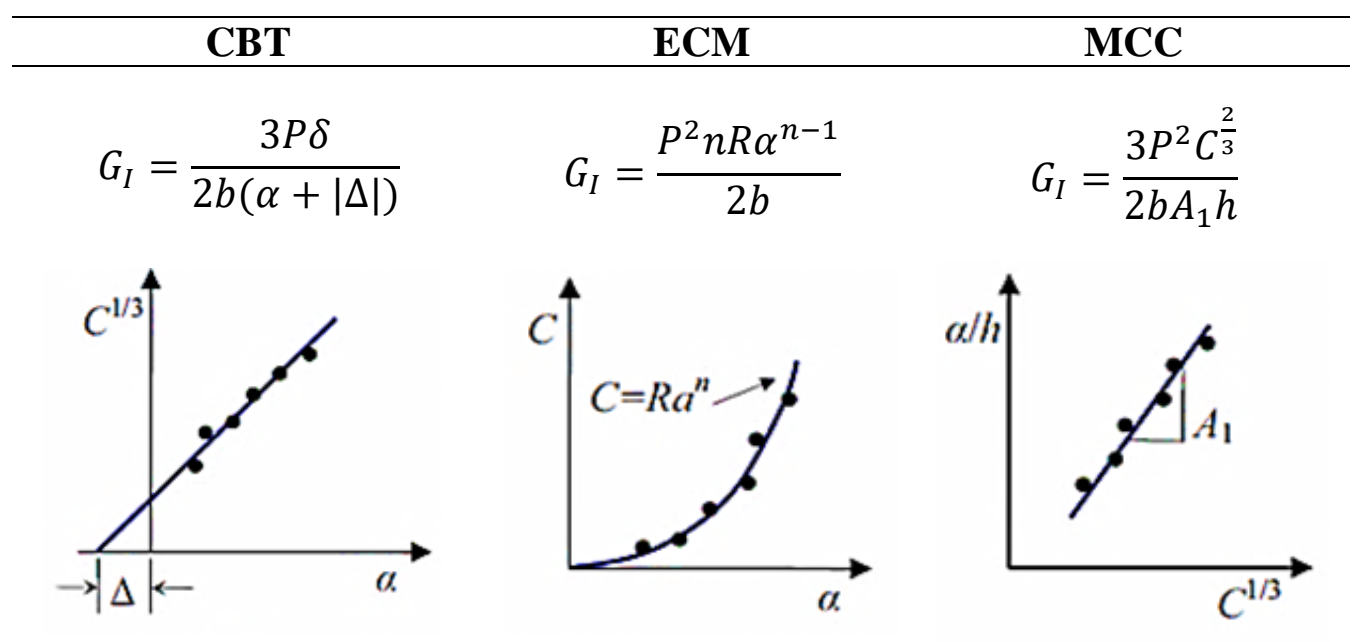

Where, $|\Delta|$ is the modification factor for the rotation of crack-tip, and is calculated by creating the linear regression of the cube root of the compliance $\left(\mathrm{C}^{1 / 3}\right)$ based on the length of delamination. Where $A_{1}$ is a compliance calibration term, taken as the slope of a straight line generated by the least-square fit of the delamination length normalized by the specimen thickness $(\alpha / h)$ versus the cubic root of the compliance.

In the same way, three different data reduction methods including Compliance Calibration Method (CCM), Corrected Beam Theory (CBT), and Compliance-Based Beam Method (CBBM) were used for the calculation of mode II energy release rate (Table 3$)$. Where $\mathrm{C}$ is the compliance of the specimen (bending displacement per unit load, $\mathrm{C}=\delta / \mathrm{P}$ ). The compliance $\mathrm{C}$ is expressed as $\left(C=C_{0}+m \alpha^{3}\right)$. Where constant term $\mathrm{C}_{0}$ equals to the initial compliance at crack initiation $\left(\alpha_{0}\right)$ and $E_{1}, E_{3}$ and $G_{13}$ are the longitudinal modulus, transverse modulus and shear modulus, respectively.

Table 3. Parameters of data reduction methods in mode II.

\begin{tabular}{ccc}
\hline CCM [24] & CBT [25] & CBBM [ 26] \\
\hline$G_{I I}=\frac{3 m \alpha^{2} P^{2}}{2 b}$ & $G_{I I}=\frac{9\left(\alpha+0.42 \Delta_{1}\right)^{2} P^{2}}{16 b^{2} h^{3} E_{1}}$ & $G_{I I}=\frac{9 \alpha_{e}^{2} P^{2}}{16 b^{2} h^{3} E_{f}}$ \\
\hline$\Delta_{1}=h \sqrt{\frac{E_{1}}{11 G_{13}}\left[3-2\left(\frac{\Gamma}{1+\Gamma}\right)^{2}\right]}, \Gamma=1.18 \frac{\sqrt{E_{1} E_{3}}}{G_{13}}, \alpha_{e}=\left[\frac{C_{c}}{C_{0 c}} \alpha_{0}^{3}+\left(\frac{C_{c}}{C_{0 c}}-1\right) \frac{2 L^{3}}{3}\right]^{\frac{1}{3}}, E_{f}=$ \\
$\frac{3 \alpha_{0}{ }^{3}+2 L^{3}}{8 b h^{3} C_{0 c}}, C_{0 c}=C_{0}-\frac{3 L}{10 G_{13} b h}, C_{c}=C-\frac{3 L}{10 G_{13} b h}, C=\frac{3 \alpha^{3}+2 L^{3}}{8 b h^{3} E_{1}}+\frac{3 L}{10 G_{13} b h}$ \\
L=sample length, b=sample width, h=sample thickness
\end{tabular}




\section{EXPERIMENTAL RESULTS}

The analysis of experimental results from DCB and ENF tests is done aiming to calculate two values, namely the mode-I (and mode-II) critical fracture energy and initial fracture toughness $\left(\mathrm{G}_{\mathrm{I}, 0}\right.$ and $\left.\mathrm{G}_{\mathrm{II}, 0}\right)$. In this study, three data reduction methods for mode I (CCM, $\mathrm{CBT}$, and $\mathrm{CBBM}$ ) and mode II (CCM, CBT, and CBBM) were used to create the corresponding R-curves in Mode I and II. Then, data systems $\mathrm{GI}_{\mathrm{I}}-\delta^{*}{ }_{\mathrm{I}}$ and $\mathrm{G}_{\mathrm{III}} \delta^{*}{ }_{\text {II }}$ were fitted using analytic functions. The corresponding curves for each sample, including different amounts of alumina nanoparticles in composite samples were extracted and then evaluated. The force-displacement curves of DCB samples with different nanoparticles wt $\%$ are presented in Figure 6.

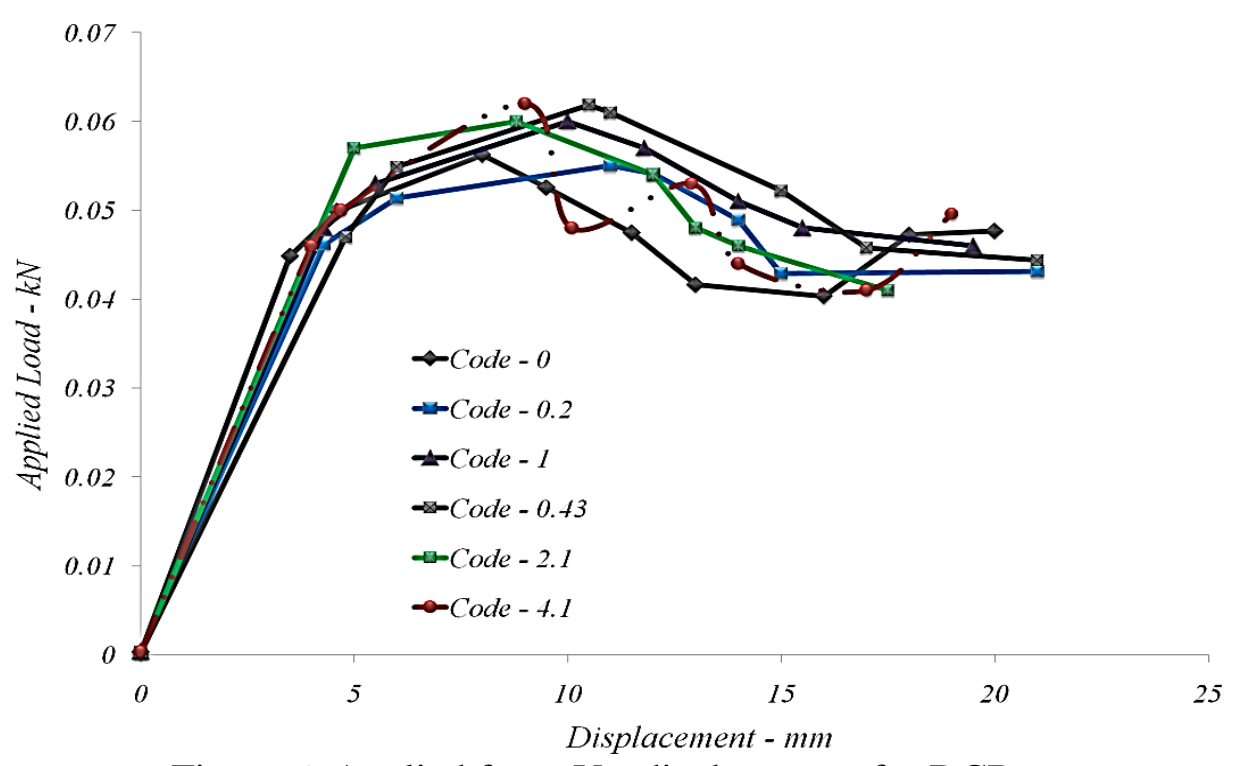

Figure 6. Applied force Vs. displacement for DCB tests.

All experimental curves show an initial linear behavior that followed by a non-linear behavior indicating the initiation of the crack growth. When it reached maximum loading value, the slope of the force-displacement curve became mild with delamination progress. Specimens do not exhibit any drop of the load after a certain maximum load level, this seems to enter into a steady-state condition. The compliance $C$ must be calculated to use in the ERR values. The ratio $C i=\delta i / P i$ has been used directly for the calculation of the compliance for each value of $\alpha i$. It is observed that the compliance of all tested specimens increases together with the cubic power of the crack length, without important changes in the slope. Hence, a linear regression based on the least square method was performed over the discrete $C-\alpha^{3}$ data sets from each DCB and ENF tests. Figures 7-9 are concerning the R-curves obtained with CBT, ECM, and MCC methods related to DCB tests. The $\mathrm{G}_{\mathrm{I}}$ increases with the growth of crack, which indicates the presence of a fiber bridging mechanism. After a certain crack length, it seems that $\mathrm{G}_{\mathrm{I}}$ converges towards a mean value (steady state fracture toughness, $\mathrm{G}_{\mathrm{I}, \mathrm{SS}}$ ). Since the main objective was to extract a rule that determines the bridging area to be used as an interface property, an analytic function (a 
fitted function), capable of estimating the trend of changes, was introduced for each sample. To apply the J-integral method, this process needed $\mathrm{G}_{\mathrm{I}}-\delta^{*}{ }_{\mathrm{I}}$ equation and thus the fabrication of an analytic shape of bridging principles. Many attempts have been made to find a fitting function capable of determining delamination adjustment coefficient $\left(\mathrm{R}^{2}\right)$ as close as possible to the unit, using the least squares technique. All three $\mathrm{G}_{\mathrm{I}}-\delta^{*}{ }_{\mathrm{I}}$ data sets were estimated, using exponential fitting function with $\mathrm{R}^{2}>0.9$ for different reduction methods. The exponential fitting function (For DCB test - mode I) is as follows [22]:

$$
G_{I}\left(\delta_{I}^{*}\right)=A \exp \left(-B * \delta_{I}^{*}\right)+C
$$

And the polynomial fitting function (For ENF test - mode II) [22]:

$$
G_{I I}\left(\delta_{I I}^{*}\right)=A \delta_{I I}^{* 2}+B \delta_{I I}^{*}+C
$$

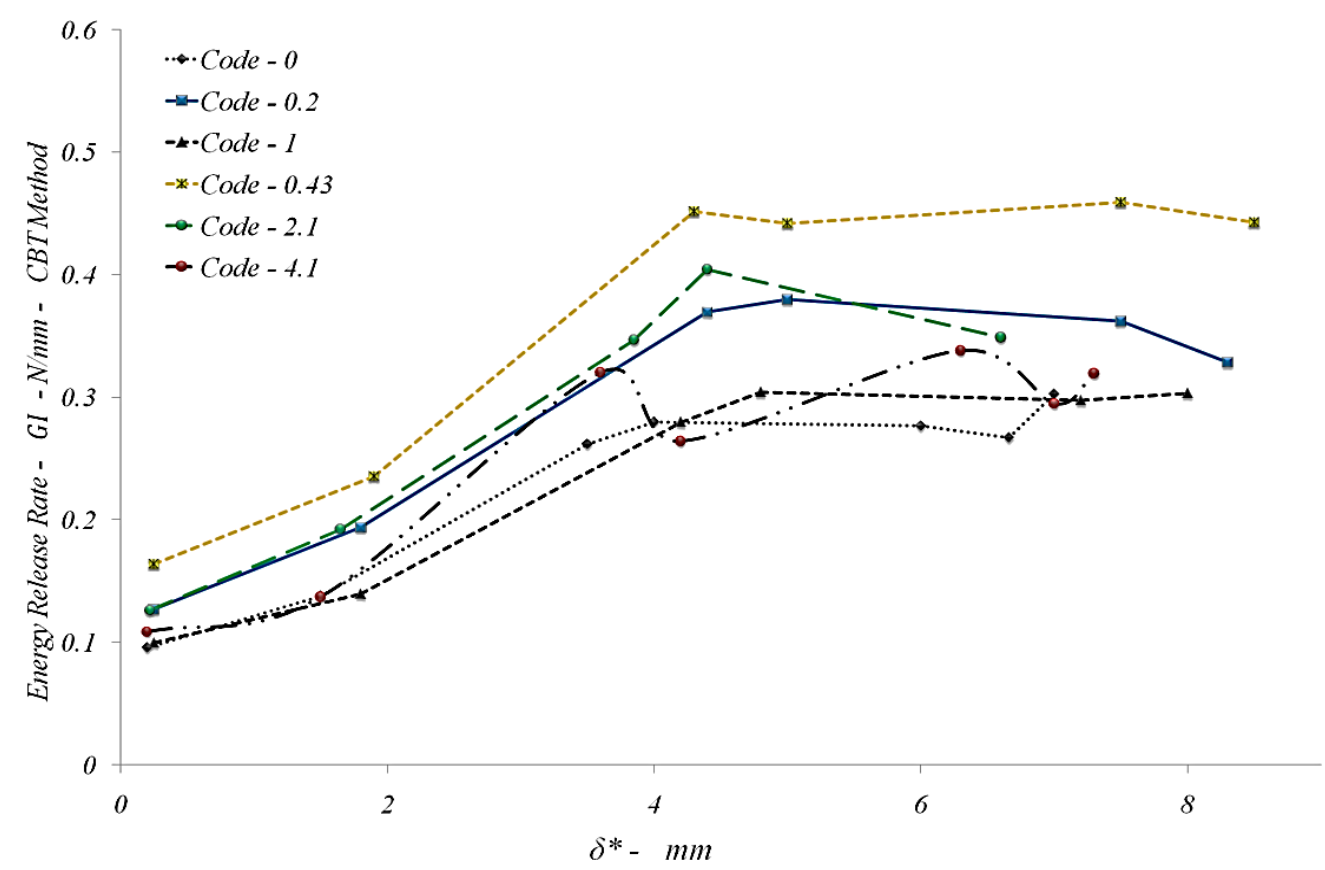

Figure 7. ERR Vs. $\delta^{*}$ for CBT method for mode I. 


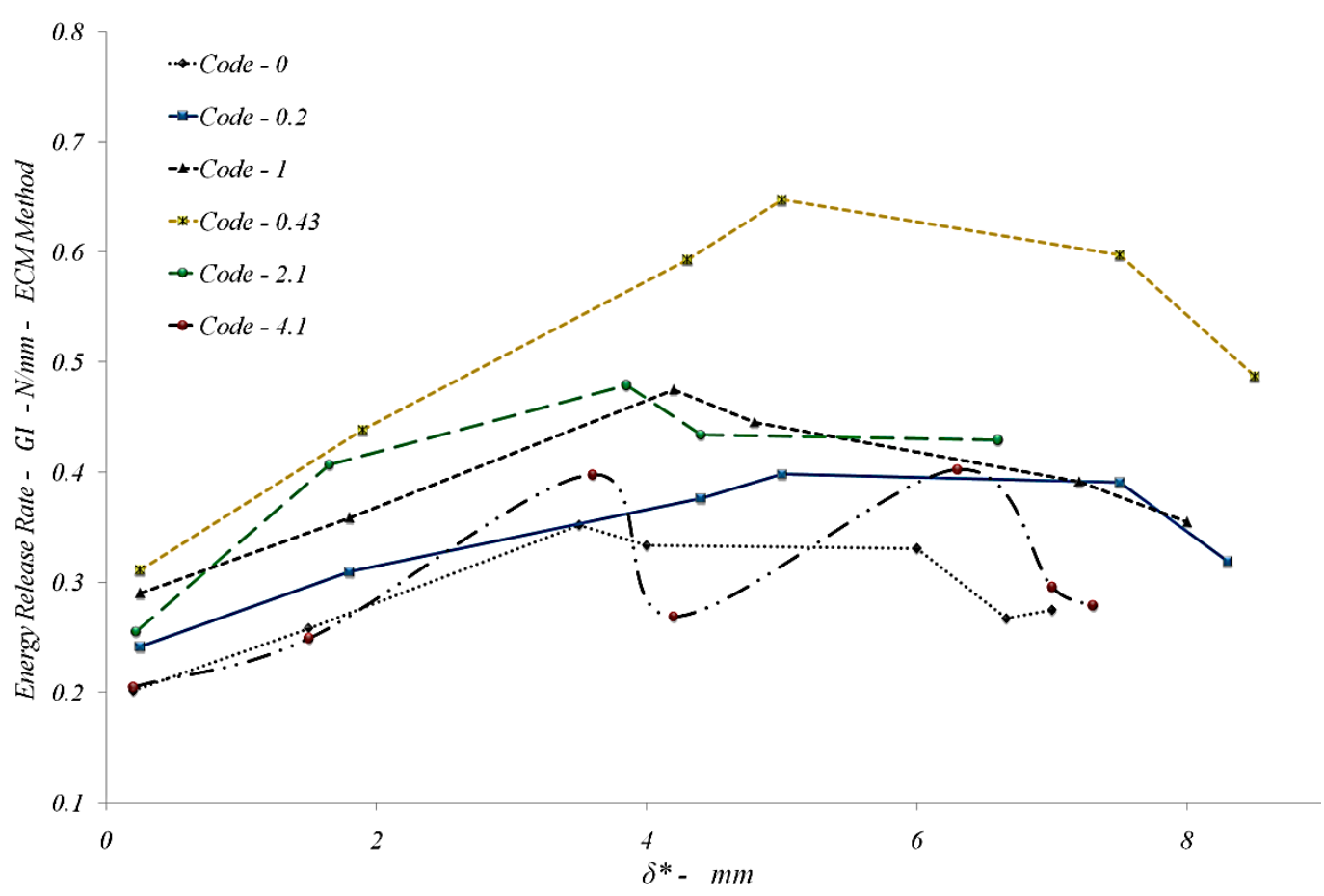

Figure 8. ERR Vs. $\delta$ * for ECM method for mode I.

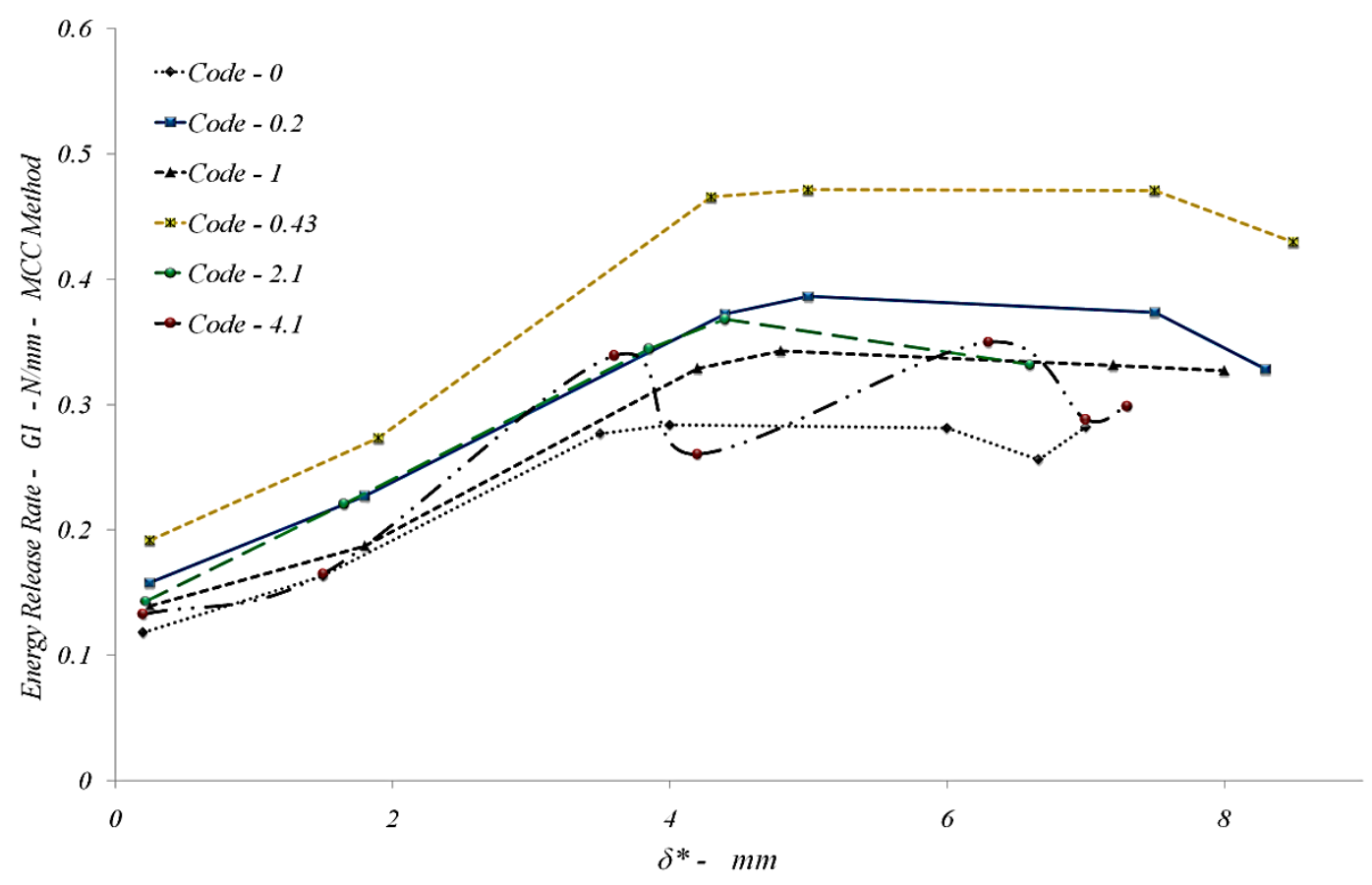

Figure 9. ERR Vs. $\delta^{*}$ for MCC method for mode I.

According to equation 1, A, B, and C are fitted coefficients for all DCB samples and energy release rate parameters are derived (Figures 11 and 12). The area under each $\sigma_{\mathrm{I}} \delta^{*}{ }_{\mathrm{I}}$ curve (is 
extracted by derivation of $\mathrm{G}_{\mathrm{I}} \delta^{*}{ }_{\mathrm{I}}$ curve). $\mathrm{G}_{\mathrm{I}, \mathrm{b}}$, is a characteristic property of the obtained bridging law which expresses the energy uptake at the completion of the bridging zone.

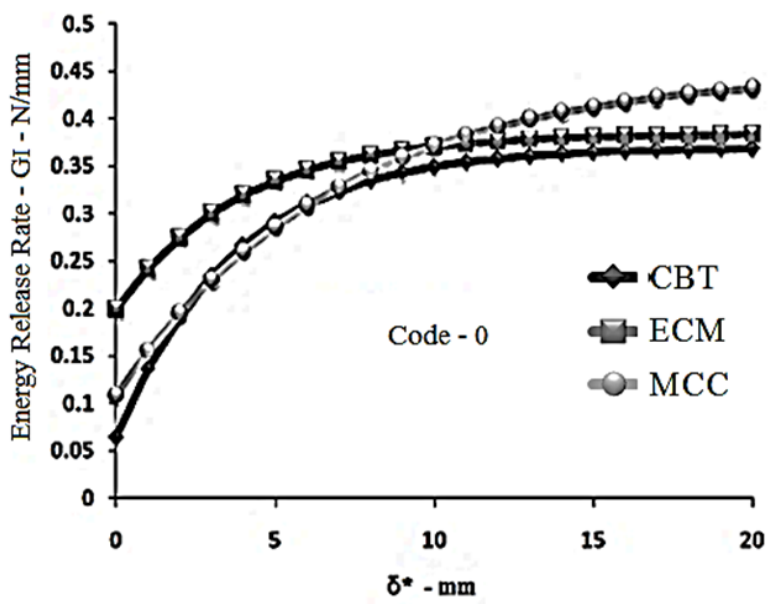

(a)

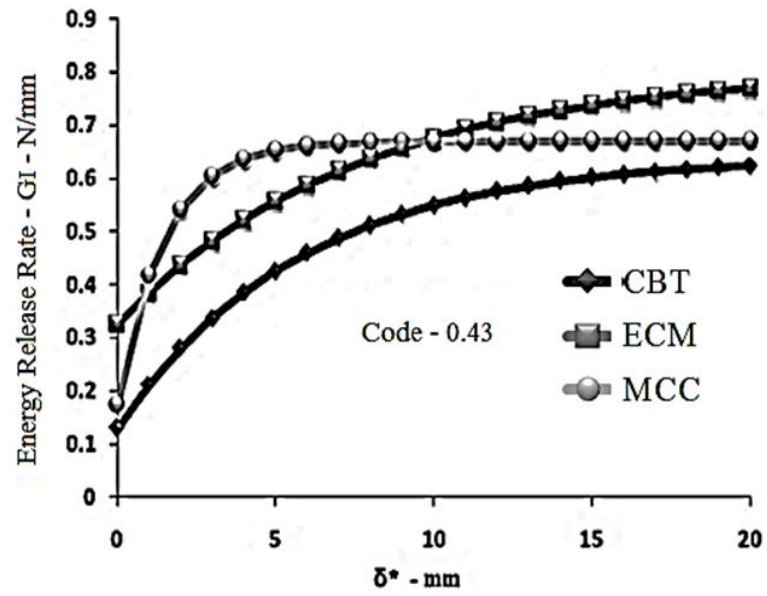

(c)

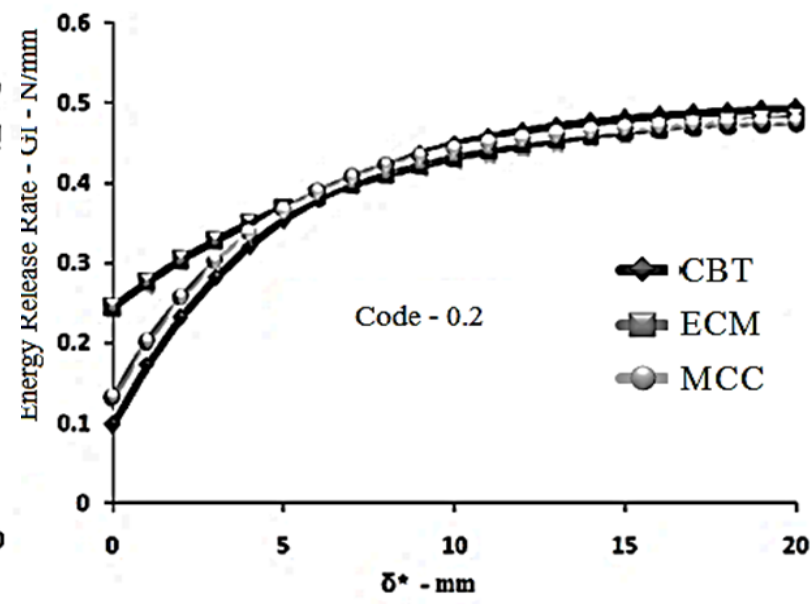

(b)

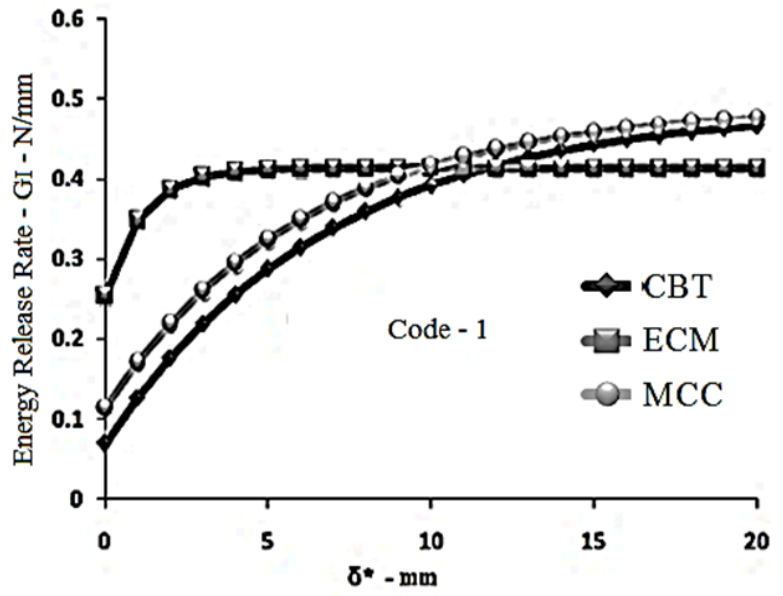

(d) 


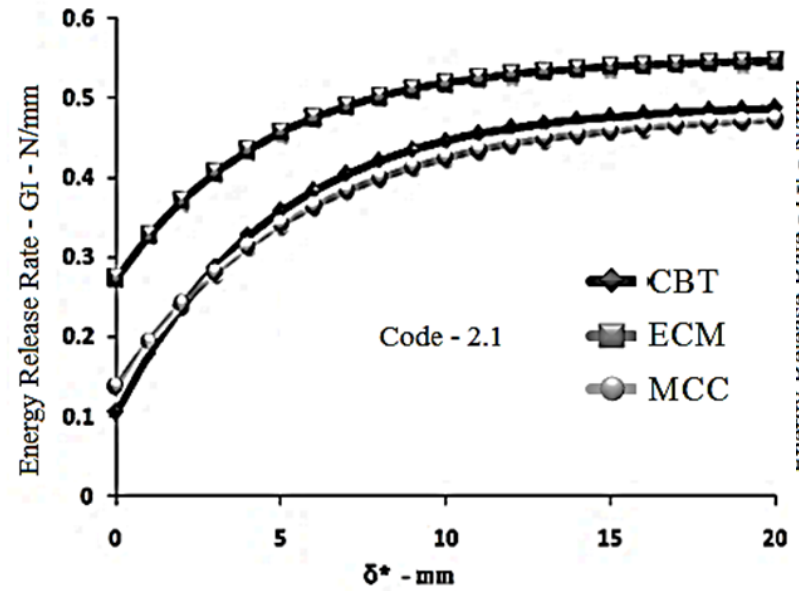

(e)

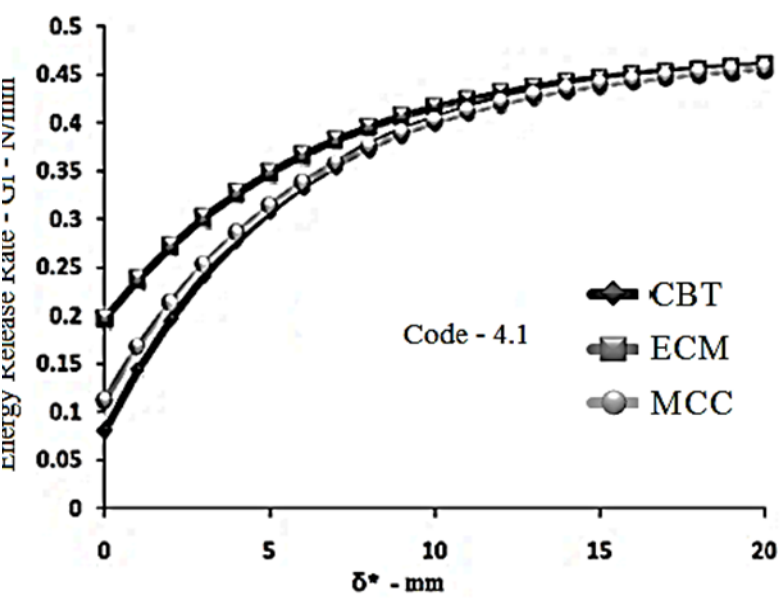

(f)

Figure 10. Energy release rate vs. $\delta^{*}$ for DCB nanocomposite samples, a) Code-0, b) Code0.2 , c) Code- 0.43 , d) Code-1, e) Code-2.1, f) Code-4.1.

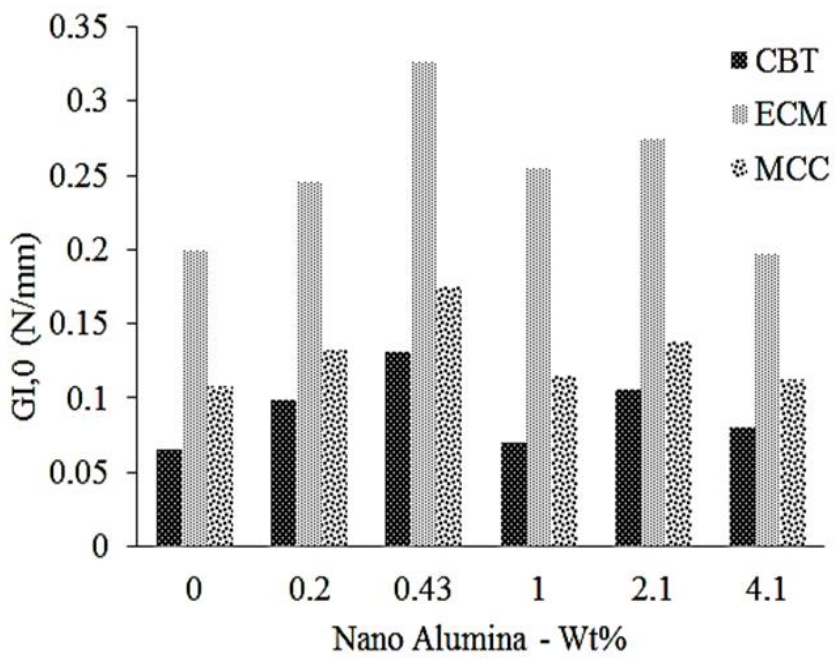

(a)

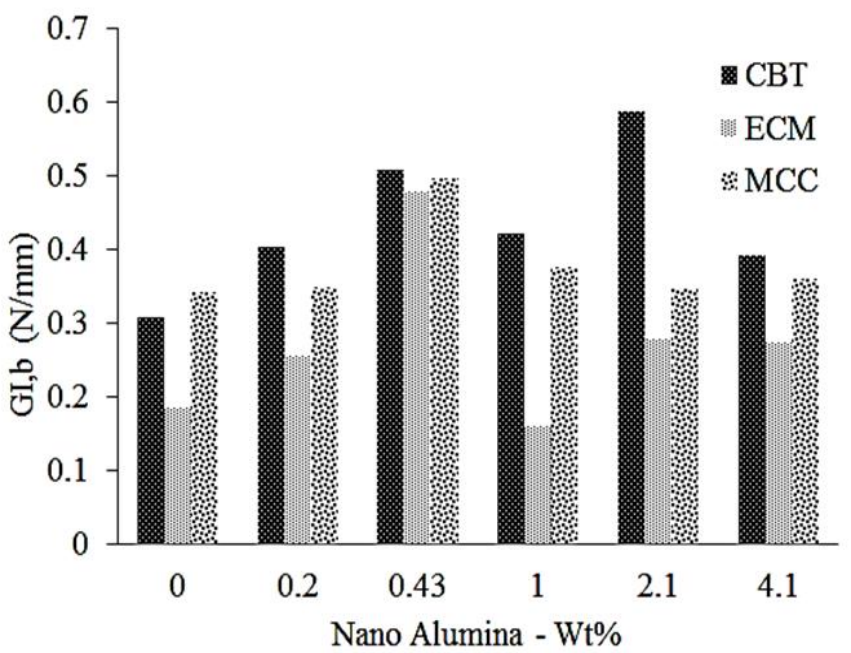

(b) 


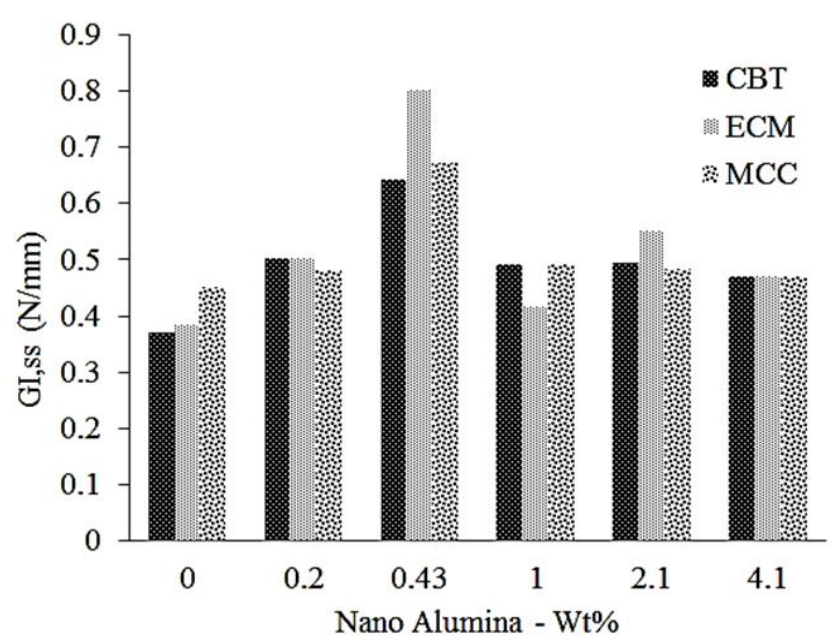

(c)

Figure 11. a) Initial energy release rate, b) bridging energy release rate, c) steady state energy release rate for mode $\mathrm{I}\left(\mathrm{G}_{\mathrm{I}, \mathrm{ss}}=\mathrm{G}_{\mathrm{I}, 0}+\mathrm{G}_{\mathrm{I}, \mathrm{b}}\right)$.

It is clear from the experimental results presented in Figure 11 that there is an inconsistency between the results of ECM and those of other two methods specially in initial energy release rate which ECM values are far higher than those of CBT and MCC. All three calculated bridging principles experience a mild exponential behavior. In stark contrast, though, the critical bridging stress $\left(\sigma_{\mathrm{c}, \mathrm{I}}\right)$ and critical crack opening displacement $\left(\delta_{\mathrm{c}, \mathrm{I}}\right)$ of bridging principles, obtained from different methods, differ from each other (Figure 12). The amount of critical bridging stress is related to the initial slope of the $G_{I}$ curve, and is calculated by applying differentiation to it. Therefore, the greater initial slope indicates a greater bridging stress, and vice versa.

Given that the information provided in Figure 11, adding $0.43 \mathrm{wt} \%$ nanoparticles to composite DCB samples gives rise to increase of $116 \%, 68 \%$ and $70 \%$ in $\mathrm{G}_{\mathrm{I}, 0}$ calculated by CBT, ECM and MCC respectively. By the same token, $72 \%$ increase in $\mathrm{G}_{\mathrm{I}, \mathrm{ss}}$ is measured by CBT, while this value for ECM and $\mathrm{MCC}$ is $110 \%$ and $48 \%$ according to the experimental observations. A glance at the information supplied for $\mathrm{G}_{\mathrm{I}, \mathrm{b}}$ in Figure 11 reveals that adding $43 \mathrm{wt} \%$ of nanoparticles leads to maximum $88 \%$ which calculated by ECM data reduction method.

Figure 12 illustrates the values of $\sigma_{\mathrm{c}, \mathrm{I}}$ and $\delta_{\mathrm{c}, \mathrm{I}}$ (bridging principles) obtained using experimental according to ECM, CBT, and MCC methods. An important point is the comparison of energy concept at the end of fracture process zone (FPZ), which is equal to the definite integral of bridging principles obtained experimentally (area under the $\sigma-\delta^{*}$ curve). The amount of this value has a good consistency with increased fracture toughness of fiber bridging $\left(\mathrm{G}_{\mathrm{I}, \mathrm{b}}\right)$, calculated by subtracting $\mathrm{G}_{\mathrm{I}, 0}$ from $\mathrm{G}_{\mathrm{I}, \mathrm{SS}}$. This fact, which is consistent with J-integral method, shows that among the obtained bridging principles, only FPZ can express the nanocomposite interface without calculating the initial ERR for crack initiation $\left(\mathrm{G}_{\mathrm{I}, 0}\right)$. According to the right hand of Figure 12, values obtained for $\delta^{*_{\mathrm{C}, \mathrm{I}}}$ by different methods have an acceptable consistency with each other with a relatively similar values other than those for the Code- 0.43 and Code- 1 . In addition, $\delta{ }^{*}$, I increases about $40 \%$ (while $190 \%$ for ECM method) with increasing nanoparticle content and then decreases. In that, the greatest $\delta^{*}$, I was observed in nanocomposite samples with 
nanoparticle content of $2.1 \mathrm{wt} \%, 1 \mathrm{wt} \%$ and $0.2 \mathrm{wt} \%$ for CBT,ECM and MCC methods respectively.

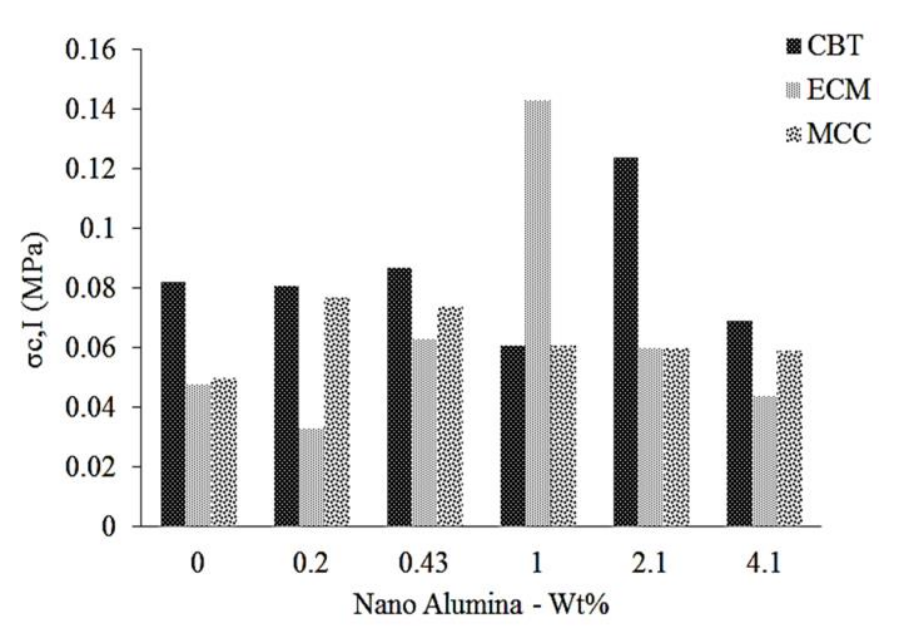

(a)

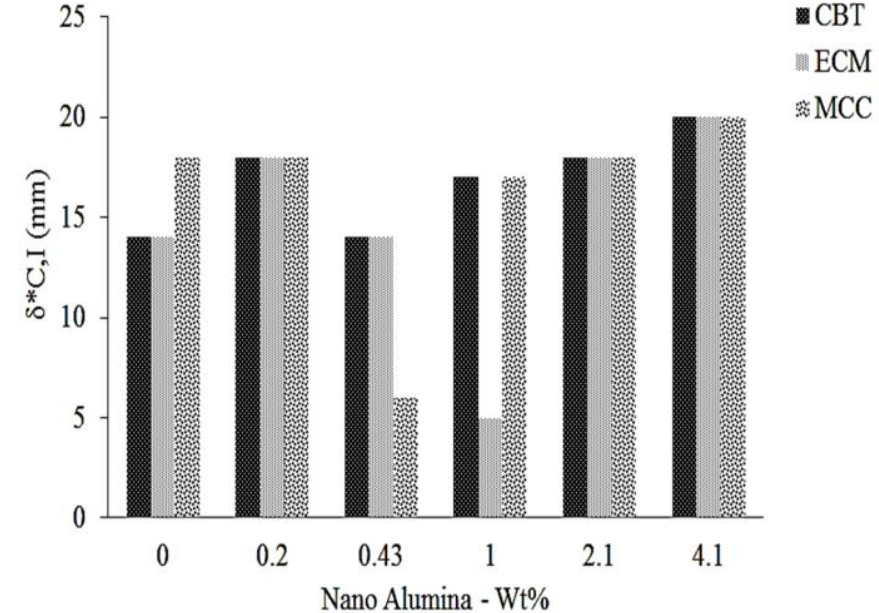

(b)

Figure 12. a) Critical stress in mode I b) ultimate opening displacement in mode I.

Generally, in CBT method, adding nanoparticles to the composite samples up to $0.43 \%$ results in increase of critical stress compared with reference sample (Code - 0), while adding $1 \mathrm{wt} \%$ nanoparticles experiences a $25 \%$ decrease and in a completely different manner this value soars to $50 \%$ by adding $2.1 \mathrm{wt} \%$. The critical stress values in mode I derived by ECM method fluctuated somewhere between just below $0.04 \mathrm{MPa}$ and somewhere in the vicinity of $0.14 \mathrm{MPa}$ belonging to the sample with $1 \mathrm{wt} \%$ nanoalumina particles. In stark contrast, though, the critical opening displacement for Code- 1 sample is the lowest value in comparison with those of the other samples in a low as $5 \mathrm{~mm}$, whereas this parameter for reference sample is $20 \mathrm{~mm}$. In MCC method, the highest critical stress belongs to the sample with $0.2 \mathrm{wt} \%$ at somewhere just below $0.08 \mathrm{MPa}$, while the maximum value for the critical displacement is calculated for Code- 4.1, 42\% higher than the reference sample.

In the same way, experimental results for mode II fracture and according to Equation 2 are derived. The force-displacement curves of ENF samples with different nanoparticle wt $\%$ are presented in Figure 13. 


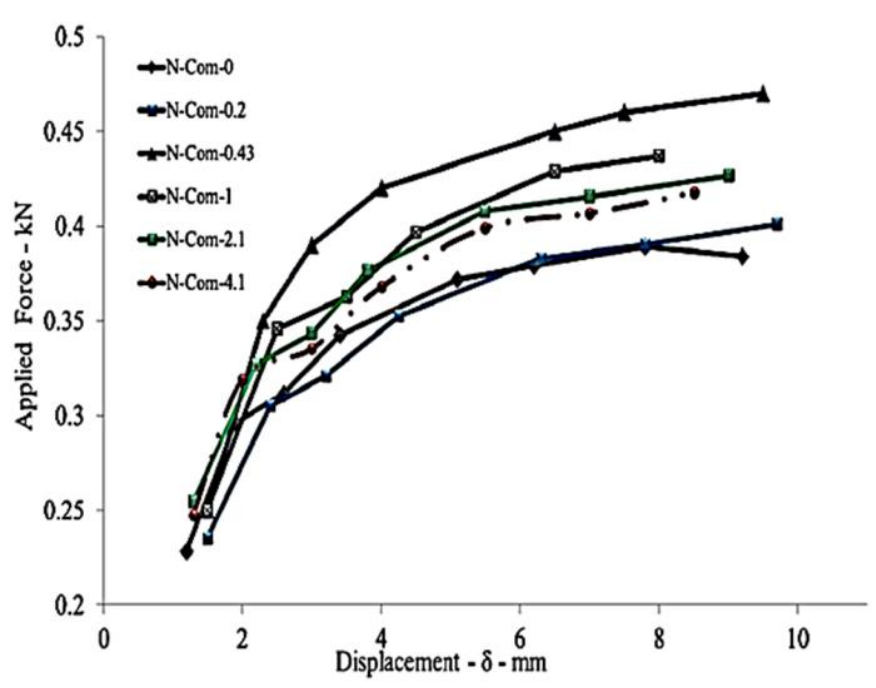

(a)

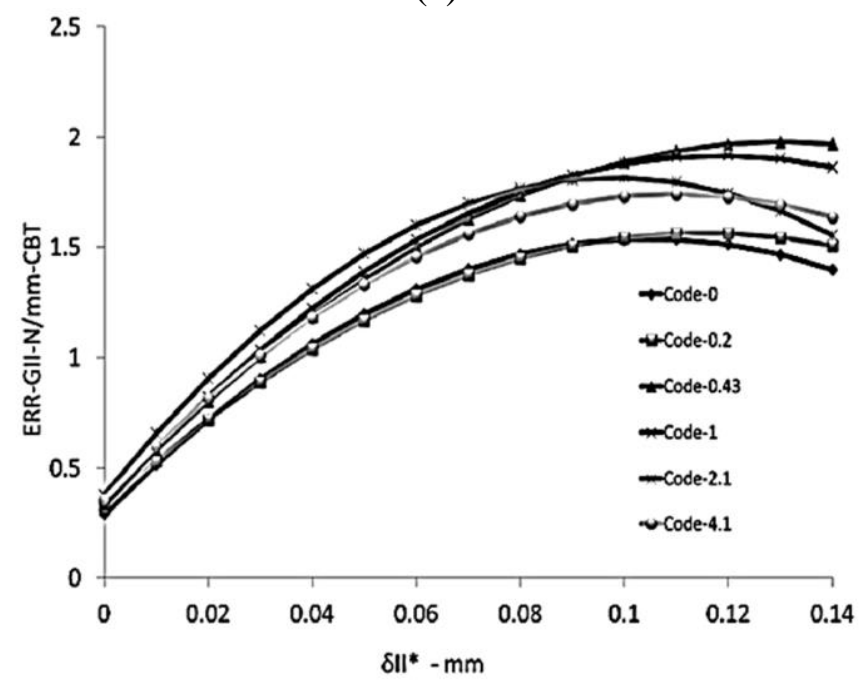

(c)

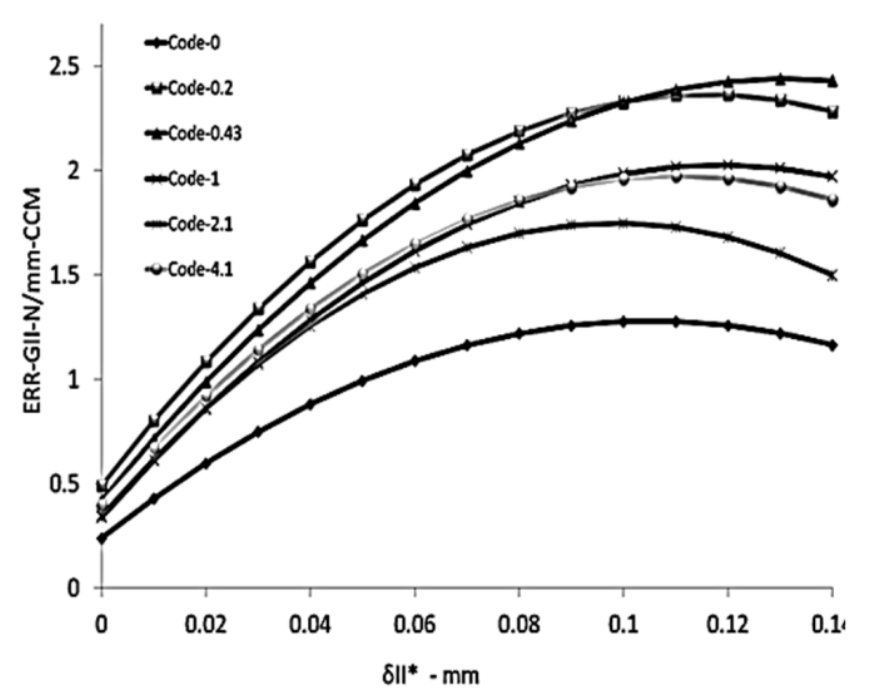

(b)

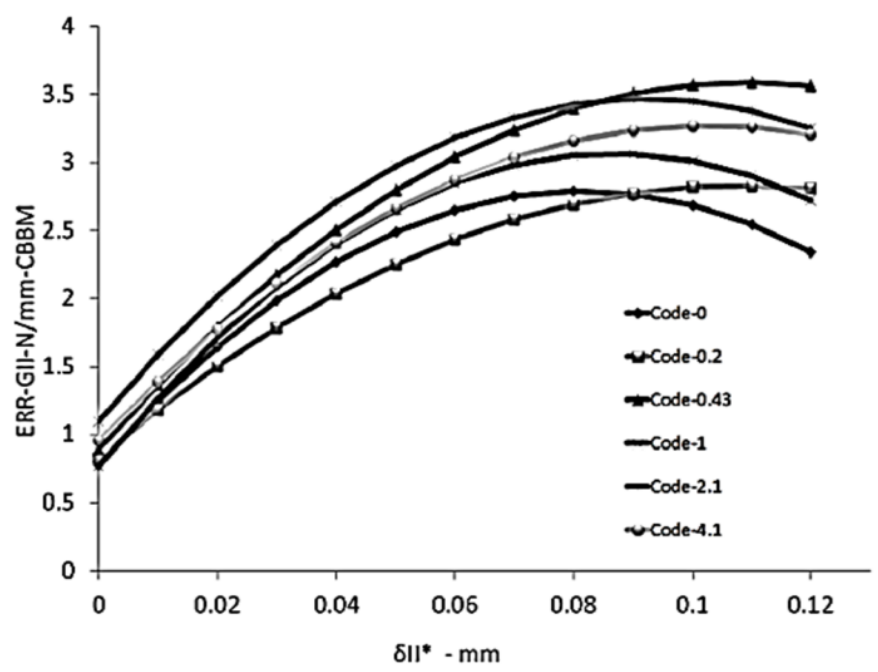

(d)

Figure 13. a) Force vs. displacement for ENF tests, b) energy release rate by CCM, c) energy release rate by $\mathrm{CBT}, \mathrm{d}$ ) energy release rate by $\mathrm{CBBM}$.

$\mathrm{A}, \mathrm{B}$, and $\mathrm{C}$ were fitted coefficients for all ENF samples according to Equation 2. All $\sigma_{\mathrm{II}^{-}}$ $\delta^{*}$ II curves presented in Figure 14 are extracted by derivation of $\mathrm{G}_{\mathrm{II}}-\delta^{*}$ II curve. Effect of Nano-particles on the experimental bridging laws including initial, bridging and steady state energy release rates in mode II derived by CCM, CBT and CBBM methods are presented in the Figure 15. 


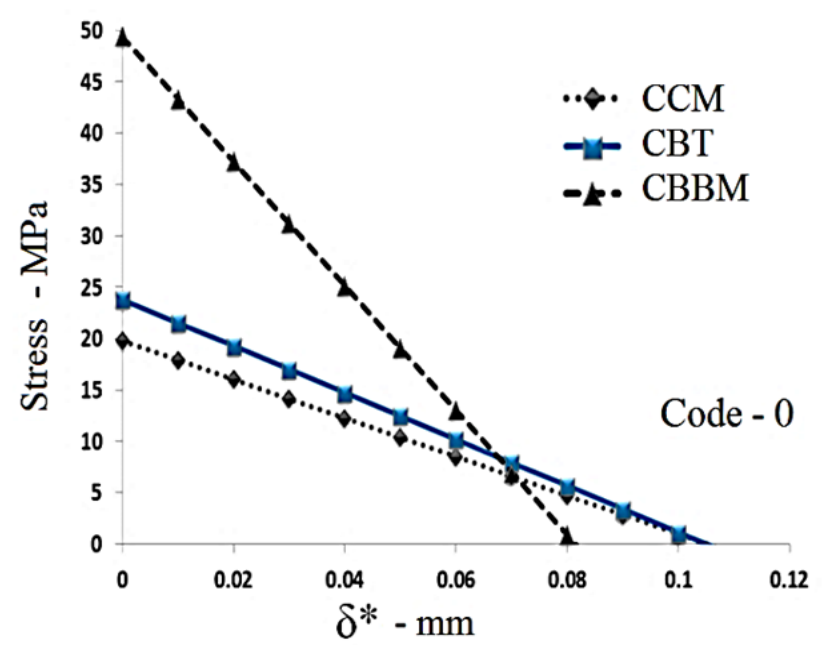

(a)

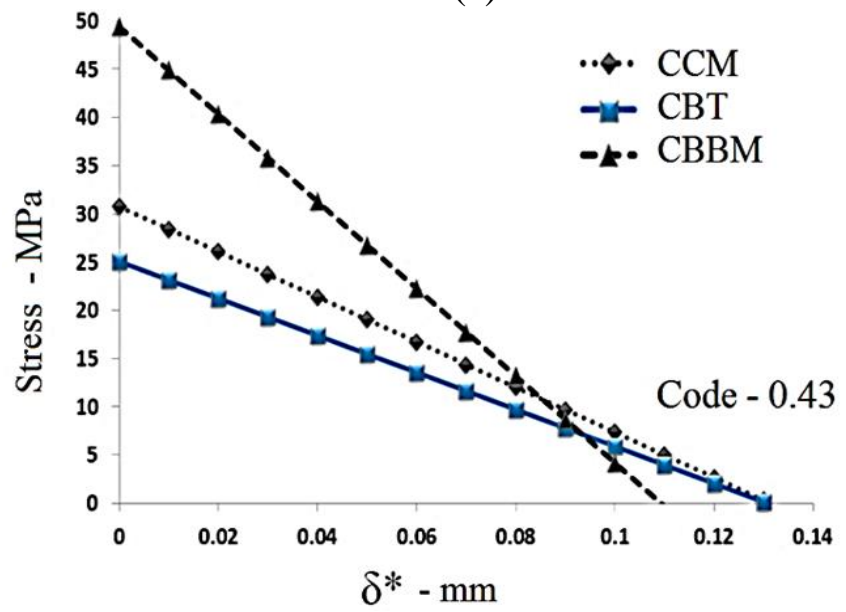

(c)

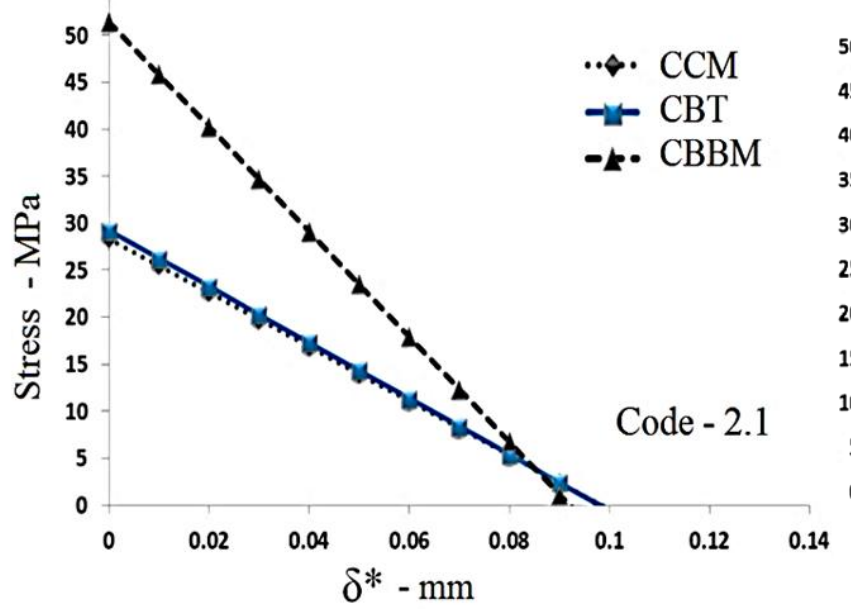

(e)

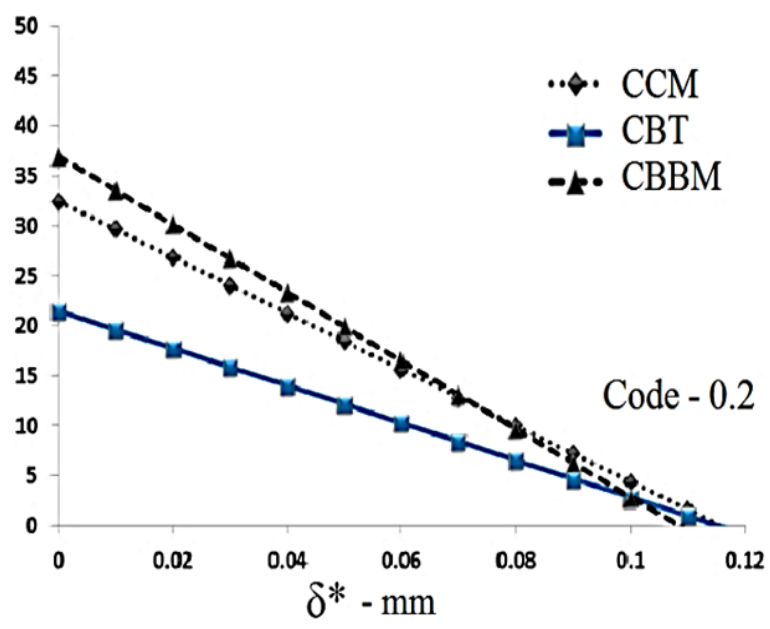

(b)

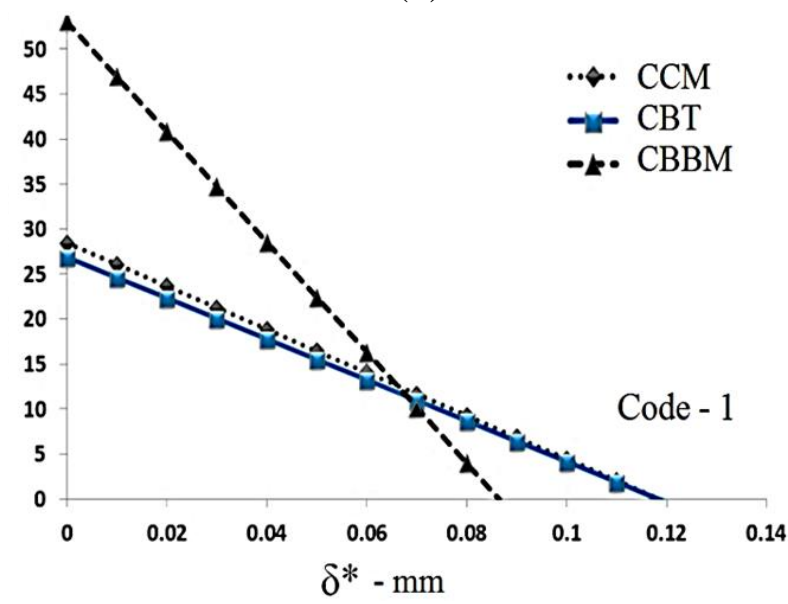

(d)

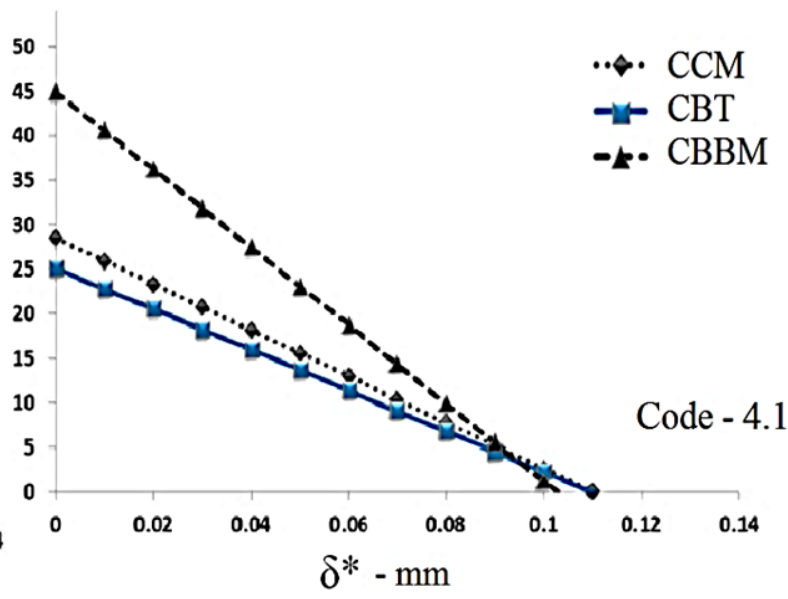

(f) 
Figure 14. Bridging laws for ENF tests, a) Code-0, b) Code-0.2, c) Code-0.43, d) Code-1,

e) Code-2.1, f) Code-4.1.

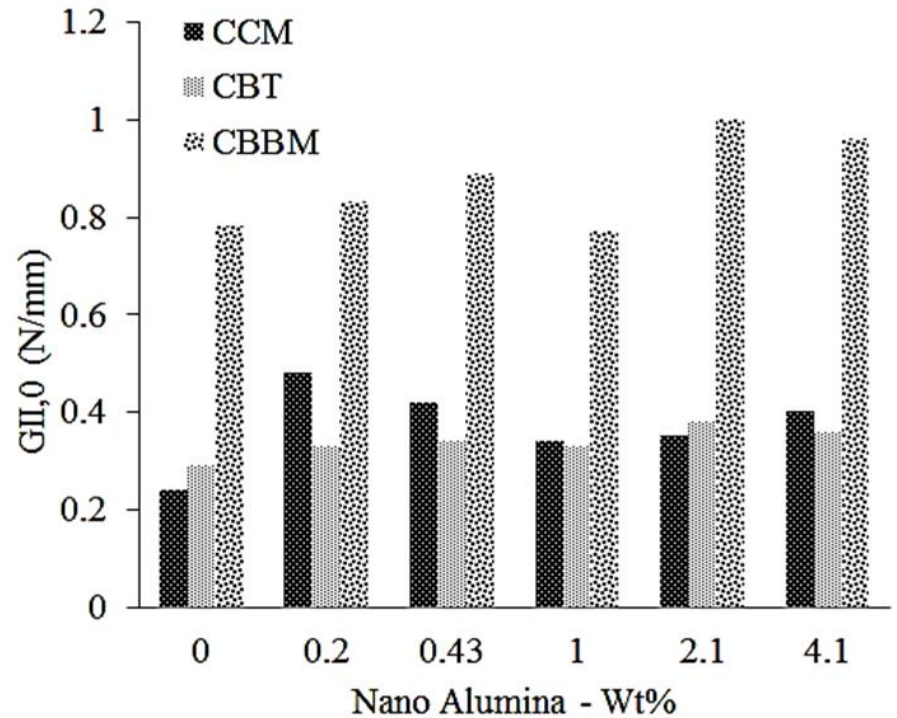

(a)

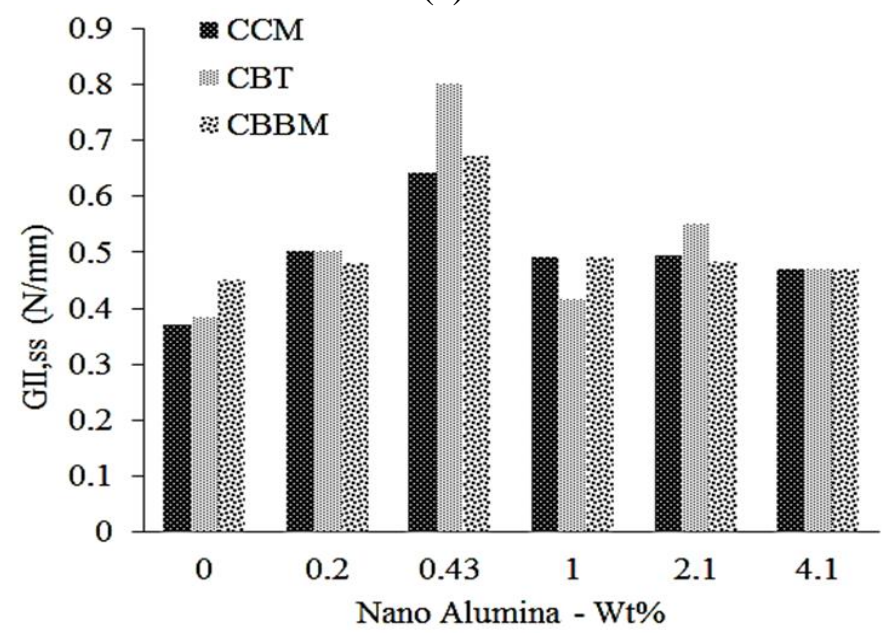

(c)

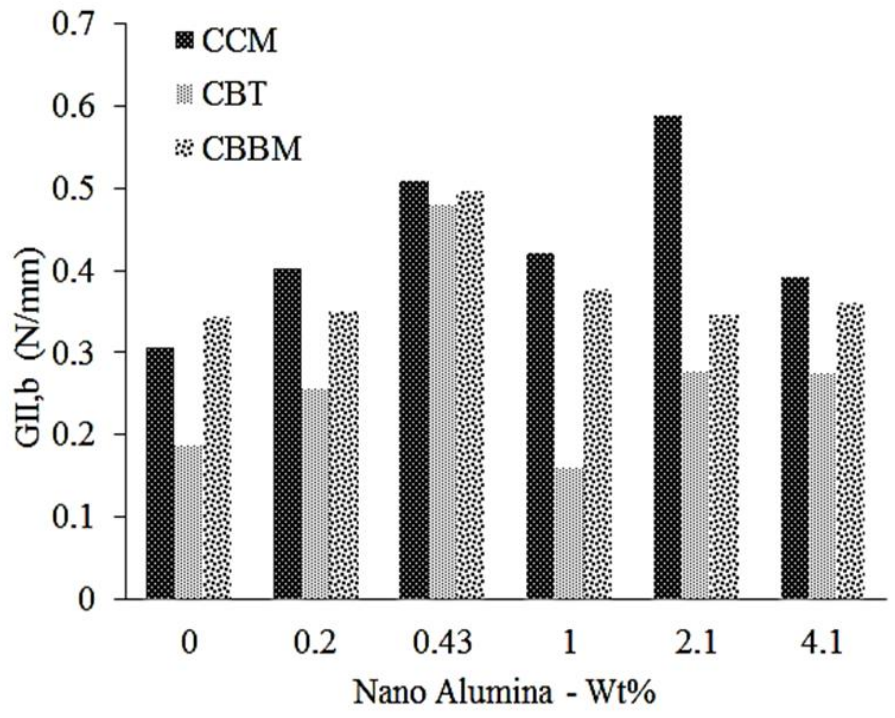

(b)

Figure 15. a) Initial energy release rate, b) bridging energy release rate, c) steady state energy release rate for mode II $\left(\mathrm{G}_{\mathrm{I}, \mathrm{ss}}=\mathrm{G}_{\mathrm{I}, 0}+\mathrm{G}_{\mathrm{I}, \mathrm{b}}\right)$.

According to Figure 16, the value of $\sigma_{\mathrm{C}, \text { II }}$ increased with addition of nanoparticles to the composite, and then starts decreasing. In that, the largest $\sigma_{\mathrm{C}, \text { II }}$ was observed in mode II samples with nanoparticle content of Code-0.2, Code-2.1 and Code-1 for Method CCM, CBT and CBBM, respectively. Generally increasing nanoparticles wt $\%$ in composite specimens have a different manner and lead to increase in values of $\mathrm{G}_{\mathrm{II}, 0}$ and $\mathrm{G}_{\mathrm{II}, \mathrm{b}}$. 


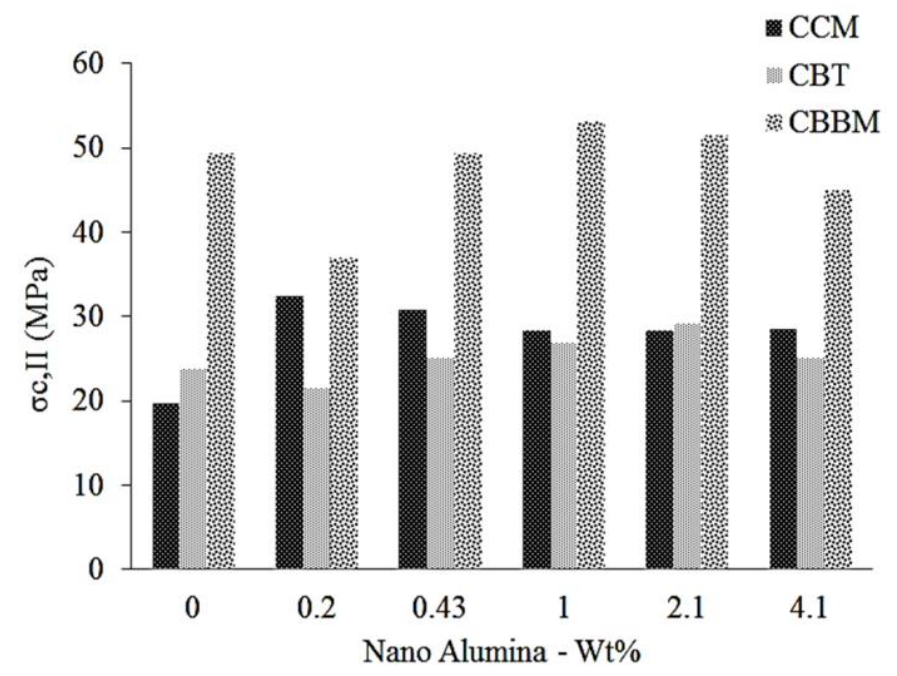

(a)

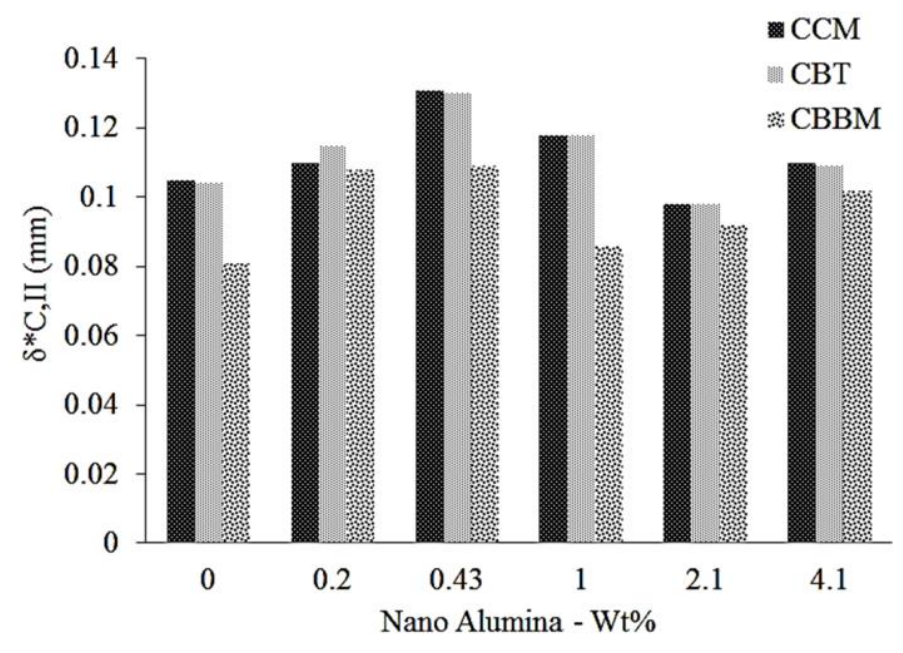

(b)

Figure 16. a) Critical stress in mode II b) ultimate sliding displacement in mode II.

It is evident from the data provided in Figure 16 that adding $0.2 \mathrm{wt} \%$ nanoparticles to the composite samples results in $64 \%$ increase in critical stress in mode II fracture calculated by method CCM, this value for CBT and CBBM methods show an increase about just $8 \%$ and as high as $86 \%$ respectively. Adding more particles have no significant change in this feature. The sample Code- 0.43 has brought the highest value for sliding displacement measured by this method and that of CBT approach. The highest amount of critical stress has been appeared in CBBM method (about $50 \mathrm{MPa}$ ), while this method presented the lowest value for critical displacement, fluctuated between $0.08-.11 \mathrm{~mm}$ in mode II. There is not a good compliance between derived experimental results by CBBM method and those of the other two schemes.

The results presented in this experimental work are compatible with the experimental work by Tsouvalis et al. [21] for mode I and II fracture calculated by these three schemes. They reported a moderate disagreement between the results obtained from the ECM for mode I and the other two methods. The accuracy of the ECM is based on the number of the discrete points used to fit the $\mathrm{C}-\alpha$ relationship and probably this is the reason for the above mentioned disagreement. With regard to numerical work, they believe that the numerical $\mathrm{P}-\delta$ curves produced when using the power and linear laws derived from the $\mathrm{CBBM}$ data reduction scheme exhibit the best agreement with the corresponding $\mathrm{P}-\delta$ experimental curves [21]. The linear traction separation model predicts very accurately both the failure load and the corresponding bending displacement value, its numerical results coinciding almost perfectly with the experimentally measured response [21]. 


\section{BRIDGING / COHESIVE LAWS}

\section{Bridging / Cohesive Law for Mode I}

The bridging rules and principles were extracted without considering the initial fracture toughness $\mathrm{G}_{\mathrm{I}, 0}$; therefore, they should be modified to fit with traction-separation laws. The downward part at the right side of the curve represents the experimental bridging principles, which was obtained via J-integral method. This curve also includes the integration of the initial linear behavior to the corresponding point of $\sigma_{\mathrm{c}, \mathrm{I}}-\delta_{0, \mathrm{I}}$. Different models have been developed to express the traction-separation curve. Some of these models and proposed modified model are presented in Figure 17.

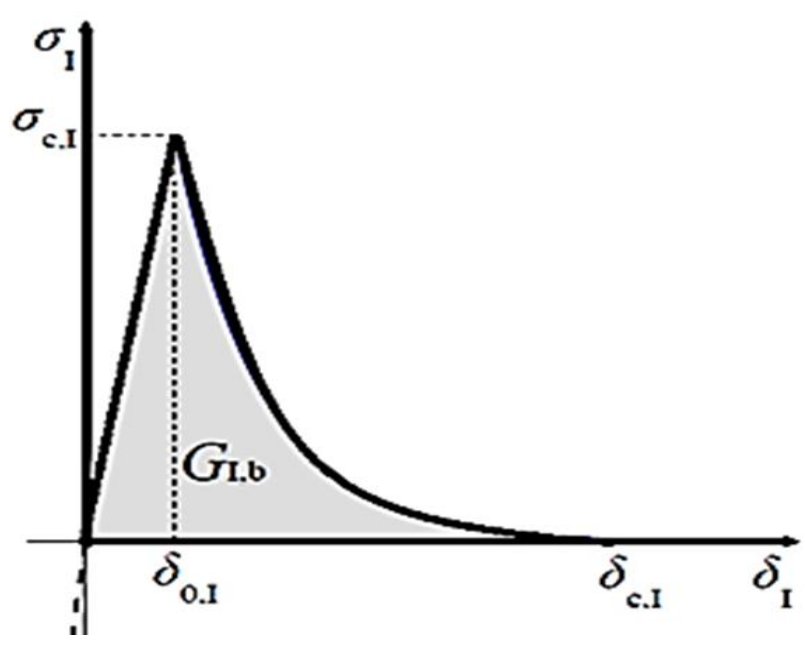

(a)

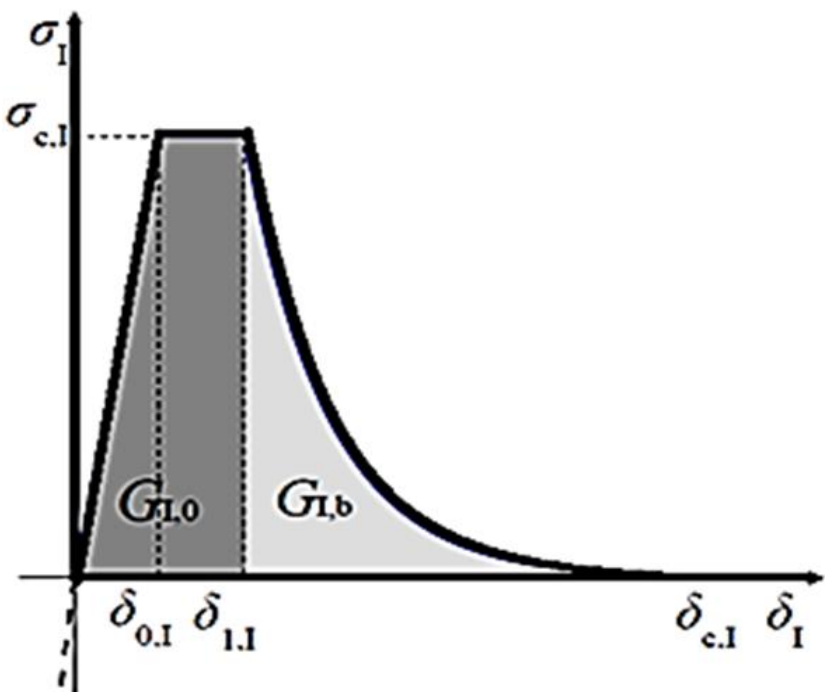

(c)

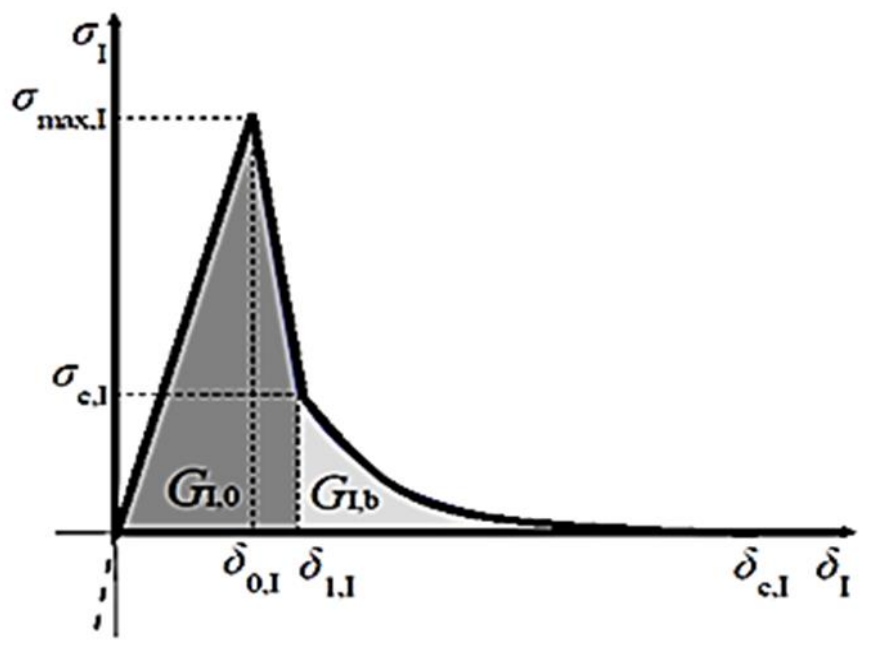

(b)

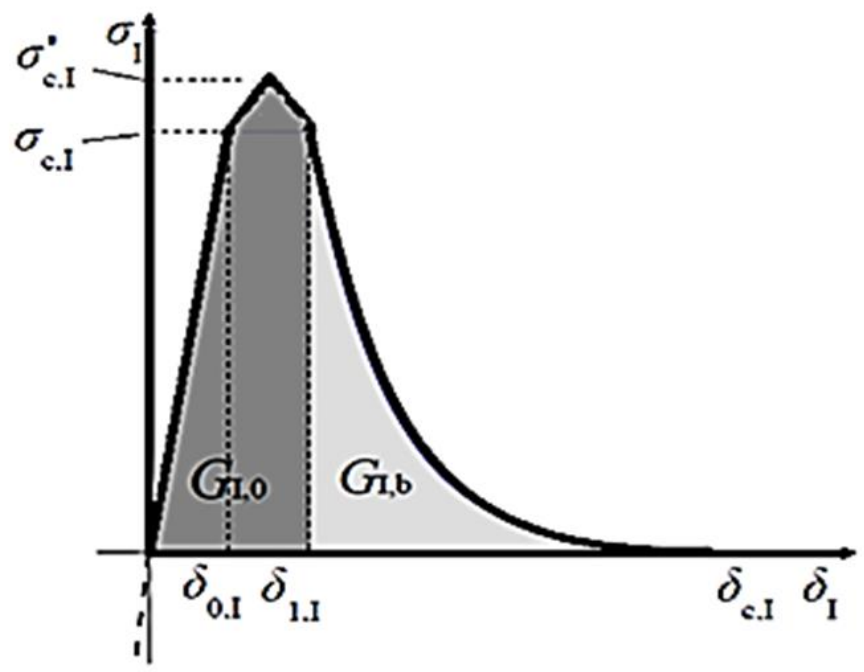

(d)

Figure 17. a) Traction-separation model without $\mathrm{G}_{\mathrm{I}, 0}$, b) 3-parameter traction-separation model, c) trapezoidal traction-separation model with exponential softening d) P1- proposed modified trapezoidal traction-separation model with exponential softening for mode I. 
This study proposed a traction-separation principle as modified trapezoidal model (P1), to investigate the inclusion of $\mathrm{G}_{\mathrm{I}, 0}$ in the experimental bridging principle (Figure 17-d).

For displacement values within $\delta_{(0, \mathrm{I})}<\delta_{\mathrm{I}} \leq \delta_{(1, \mathrm{I})}$, following equation was used to express the stress $\left(\sigma_{\mathrm{C}, \mathrm{I}}^{\prime}=1.1 \sigma_{\mathrm{C}, \mathrm{I}}\right)$ :

$\sigma_{I}\left(\delta_{I}\right)-\sigma_{C, I}^{\prime}=\frac{0.2 * \sigma_{C, I}}{\left(\delta_{1, I}-\delta_{0, I}\right)}\left(\delta_{I}-\frac{\left(\delta_{1, I}+\delta_{0, I}\right)}{2}\right)$

For $\delta_{0, I}<\delta_{I} \leq \frac{\left(\delta_{1, I}+\delta_{0, I}\right)}{2}$

$\sigma_{I}\left(\delta_{I}\right)-\sigma_{C, I}^{\prime}=-\frac{0.2 * \sigma_{C, I}}{\left(\delta_{1, I}-\delta_{0, I}\right)}\left(\delta_{I}-\frac{\left(\delta_{1, I}+\delta_{0, I}\right)}{2}\right)$

For $\frac{\left(\delta_{1, I}+\delta_{0, I}\right)}{2}<\delta_{I} \leq \delta_{1, I}$

The surface area under the curve between $\delta_{\mathrm{I}}=0$ and $\mathrm{I}=\delta_{1, \mathrm{I}}$ (Figure $17-\mathrm{d}$ ) refers to the value of $\mathrm{G}_{\mathrm{I}, 0}$, which is obtained from following equation.

$G_{I, 0}=\frac{1}{2} \sigma_{C, I} \delta_{0, I}+\sigma_{C, I}\left(\delta_{1, I}-\delta_{0, I}\right)+\frac{1}{20} \sigma_{C, I} \frac{\left(\delta_{1, I}+\delta_{0, I}\right)}{2}$

By having the values of $\mathrm{G}_{\mathrm{I}, 0}$ and $\delta_{0, \mathrm{I}}$, the value of $\delta_{1, \mathrm{I}}$ can be easily obtained using Equation 4. After the completion of the crack growth in $\delta_{1, \mathrm{I}}$, normal stresses $\sigma_{\mathrm{I}}$ are removed based on the exponential softening behavior obtained from experimental bridging principles. Therefore, for the separation values $\left(\delta_{\mathrm{I}}\right)$ larger than $\delta_{1, \mathrm{I}}$, stresses are obtained from following equation.

$\sigma_{I}\left(\delta_{I}\right)=\sigma_{C, I} \exp \left(-\left(\delta_{I}-\delta_{1, I}\right) \sigma_{C, I} / G_{I, 0}\right)$ For $\delta_{1, I}<\delta_{I} \leq \delta_{C, I}$

$\delta_{C, I}=\delta_{1, I}+\delta_{C, I}^{*}$

When $\delta_{\mathrm{I}}$ is larger than $\delta_{\mathrm{c}, \mathrm{I}}$, the bridging fibers lose their load bearing capacity and yield. Therefore, stresses are eliminated. By placing $\mathrm{G}_{\mathrm{I}, 0}$ in the proposed traction-separation equation, the total consumption of energy at the end of FPZ becomes equal to the desired amount of ERR, which is equal to the steady-state fracture toughness of $\mathrm{G}_{\mathrm{I}, \mathrm{SS}}$ and expressed with the surface area under the $\sigma_{\mathrm{I}}-\delta_{\mathrm{I}}$ curve (Figure $17-\mathrm{d}$ ).

$$
\begin{gathered}
G_{I, S S}=\frac{1}{2} \sigma_{C, I} \delta_{0, I}+\sigma_{C, I}\left(\delta_{1, I}-\delta_{0, I}\right)+\frac{1}{20} \sigma_{C, I} \frac{\left(\delta_{1, I}+\delta_{0, I}\right)}{2}+G_{I, 0}\left[\exp \left(-\frac{\delta_{1, I} \sigma_{C, I}}{G_{I, 0}}\right)\right. \\
\left.-\exp \left(-\frac{\delta_{C, I} \sigma_{C, I}}{G_{I, 0}}\right)\right]
\end{gathered}
$$

The parameters of the modified proposed traction-separation model (P1) used for the simulation of the DCB tests are presented in following table. 
Table 4. Experimental parameters for traction-separation law in Mode I.

\begin{tabular}{|c|c|c|c|c|c|c|c|c|}
\hline \multicolumn{7}{|c|}{ Experimental parameters for P1- model } & \multirow{2}{*}{$\begin{array}{c}\begin{array}{c}\text { Trapezoidal } \\
\text { model }\end{array} \\
\delta_{1, \mathrm{I}} \\
(\mathrm{mm})\end{array}$} & \multirow{2}{*}{$\begin{array}{c}\begin{array}{c}\text { P1- } \\
\text { model }\end{array} \\
\delta_{1, \mathrm{I}} \\
(\mathrm{mm})\end{array}$} \\
\hline & $\begin{array}{c}\sigma_{\mathrm{C}, \mathrm{I}} \\
(\mathrm{MPa})\end{array}$ & $\begin{array}{c}\delta_{0, \mathrm{I}} \\
(\mathrm{mm})\end{array}$ & $\begin{array}{c}\delta_{\mathrm{C}, \mathrm{I}}^{*} \\
(\mathrm{~mm})\end{array}$ & $\begin{array}{c}\mathrm{G}_{\mathrm{I}, 0} \\
(\mathrm{~N} / \mathrm{mm})\end{array}$ & $\begin{array}{c}\delta_{\mathrm{C}, \mathrm{I}} \\
(\mathrm{mm})\end{array}$ & $\begin{array}{c}\mathrm{G}_{\mathrm{I}, \mathrm{b}} \\
(\mathrm{N} / \mathrm{mm})\end{array}$ & & \\
\hline \multicolumn{9}{|c|}{ Code- 0} \\
\hline $\mathrm{CBT}$ & 0.082 & $82 \mathrm{E}-8$ & 14 & 0.0642 & 14.74 & 0.3058 & 0.78 & 0.74 \\
\hline ECM & 0.048 & $48 \mathrm{E}-8$ & 14 & 0.1989 & 17.94 & 0.1851 & 4.14 & 3.94 \\
\hline $\mathrm{MCC}$ & 0.05 & $50 \mathrm{E}-8$ & 18 & 0.108 & 20.05 & 0.342 & 2.16 & 2.05 \\
\hline \multicolumn{9}{|c|}{ Code- 0.2} \\
\hline $\mathrm{CBT}$ & 0.081 & $81 \mathrm{E}-8$ & 18 & 0.0984 & 19.15 & 0.4016 & 1.21 & 1.15 \\
\hline ECM & 0.033 & $33 \mathrm{E}-8$ & 18 & 0.2446 & 25.05 & 0.2554 & 7.41 & 7.05 \\
\hline $\mathrm{MCC}$ & 0.077 & $77 \mathrm{E}-8$ & 18 & 0.1313 & 19.62 & 0.3487 & 1.7 & 1.62 \\
\hline \multicolumn{9}{|c|}{ Code- 0.43} \\
\hline $\mathrm{CBT}$ & 0.087 & $87 \mathrm{E}-8$ & 14 & 0.1302 & 15.42 & 0.5068 & 1.49 & 1.42 \\
\hline ECM & 0.063 & $63 \mathrm{E}-8$ & 14 & 0.3258 & 18.92 & 0.4778 & 5.17 & 4.92 \\
\hline $\mathrm{MCC}$ & 0.074 & $74 \mathrm{E}-8$ & 6 & 0.174 & 8.23 & 0.496 & 2.35 & 2.23 \\
\hline \multicolumn{9}{|c|}{ Code- 1} \\
\hline $\mathrm{CBT}$ & 0.061 & $61 \mathrm{E}-8$ & 17 & 0.0694 & 18.08 & 0.4206 & 1.13 & 1.083 \\
\hline ECM & 0.143 & $143 \mathrm{E}-8$ & 5 & 0.2542 & 6.69 & 0.1597 & 1.77 & 1.69 \\
\hline $\mathrm{MCC}$ & 0.061 & $61 \mathrm{E}-8$ & 17 & 0.1147 & 18.79 & 0.3753 & 1.88 & 1.79 \\
\hline \multicolumn{9}{|c|}{ Code- 2.1} \\
\hline $\mathrm{CBT}$ & 0.124 & $124 \mathrm{E}-8$ & 18 & 0.1052 & 18.80 & 0.5872 & 0.84 & 0.80 \\
\hline ECM & 0.06 & $60 \mathrm{E}-8$ & 18 & 0.2738 & 22.34 & 0.2762 & 4.56 & 4.34 \\
\hline $\mathrm{MCC}$ & 0.06 & $60 \mathrm{E}-8$ & 18 & 0.1378 & 20.18 & 0.3454 & 2.29 & 2.18 \\
\hline \multicolumn{9}{|c|}{ Code-4.1 } \\
\hline $\mathrm{CBT}$ & 0.069 & $69 \mathrm{E}-8$ & 20 & 0.08 & 21.10 & 0.39 & 1.15 & 1.10 \\
\hline ECM & 0.044 & $44 \mathrm{E}-8$ & 20 & 0.1963 & 24.24 & 0.2737 & 4.46 & 4.24 \\
\hline $\mathrm{MCC}$ & 0.059 & 59E-8 & 20 & 0.1116 & 21.8 & 0.3584 & 1.89 & 1.80 \\
\hline
\end{tabular}

In general, values obtained from the ECM method are larger than values obtained from CBT and MCC methods. In addition, values extracted with trapezoidal models and the modified proposed model (P1) has a good consistency. Tsouvalis et al. [21] numerically compared the values obtained from the trapezoidal model and linear two-parameter model (Figure 17-a) with experimental values. They showed that the obtained results had a good consistency with experimental results when $\mathrm{G}_{\mathrm{I}, 0}$ was taken into account.

\section{Bridging / Cohesive Law for Mode II}

In the same way, Trapezoidal model and proposed model P2 (modified trapezoidal model) for mode II are presented in Figure 18. 


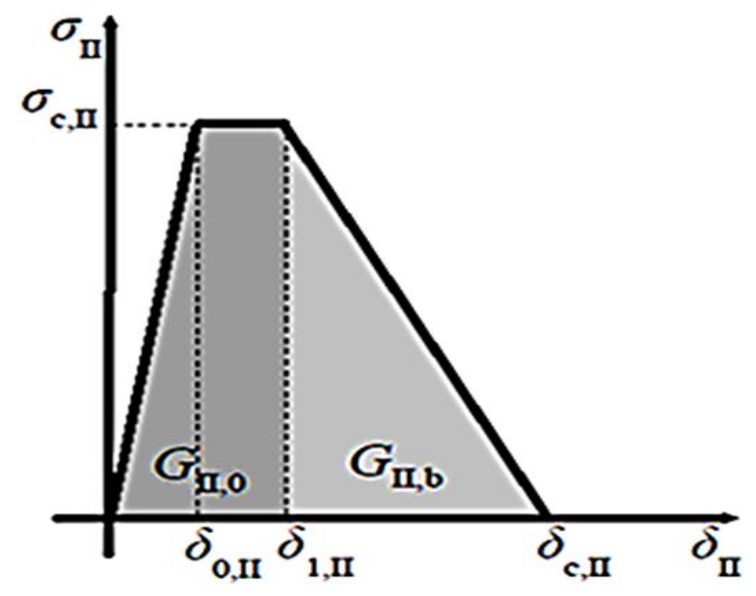

(a)

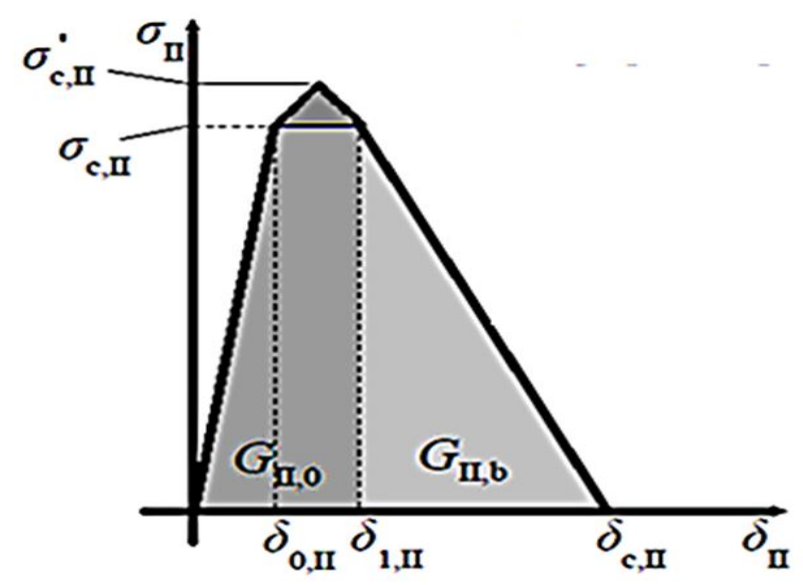

(b)

Figure 18. a) Trapezoidal traction-separation model b) P2- proposed modified trapezoidal traction-separation model for mode II.

This study proposed a traction-separation principle as modified trapezoidal model ( $\mathrm{P} 2)$, to investigate the inclusion of $\mathrm{G}_{\mathrm{II}, 0 \text { in }}$ the experimental bridging principle (Fig. 18-b). The main advantage of this method is that it does not need additional parameters to achieve numerical convergence. For displacement values within $\delta_{(0, \mathrm{II})}<\delta_{\mathrm{II}} \leq \delta_{(1, \mathrm{II})}$, following equation was used to express the stress $\left(\sigma_{\mathrm{C}, \mathrm{II}}^{\prime}=1.1 \sigma_{\mathrm{C}, \mathrm{II}}\right)$ :

The surface area under the curve between $\delta_{\mathrm{II}}=0$ and $\mathrm{I}=\delta_{1, \mathrm{II}}($ Figure 18) refers to the value of $\mathrm{G}_{\mathrm{II}, 0}$, which is obtained from following equation.

$\sigma_{I I}\left(\delta_{I I}\right)-\sigma_{C, I I}{ }^{\prime}=\frac{0.2 * \sigma_{C, I I}}{\left(\delta_{1, I I}-\delta_{0, I I}\right)}\left(\delta_{I I}-\frac{\left(\delta_{1, I I}+\delta_{0, I I}\right)}{2}\right)$

For $\delta_{0, I I}<\delta_{I I} \leq \frac{\left(\delta_{1, I I}+\delta_{0, I I}\right)}{2}$

$\sigma_{I I}\left(\delta_{I I}\right)-\sigma_{C, I I}{ }^{\prime}=-\frac{0.2 * \sigma_{C, I I}}{\left(\delta_{1, I I}-\delta_{0, I I}\right)}\left(\delta_{I I}-\frac{\left(\delta_{1, I I}+\delta_{0, I I}\right)}{2}\right)$

For $\quad \frac{\left(\delta_{1, I I}+\delta_{0, I I}\right)}{2}<\delta_{I I} \leq \delta_{1, I I}$

$G_{I I, 0}=\frac{1}{2} \sigma_{C, I I} \delta_{0, I I}+\sigma_{C, I I}\left(\delta_{1, I I}-\delta_{0, I I}\right)+\frac{1}{20} \sigma_{C, I I} \frac{\left(\delta_{1, I I}+\delta_{0, I I}\right)}{2}$

By having the values of $\mathrm{G}_{\mathrm{II}, 0}$ and $\delta_{0, \mathrm{II}}$, the value of $\delta_{1, \mathrm{II}}$ can be easily obtained using Equation 9. After the completion of the crack growth in $\delta_{1, \text { III }}$, normal stresses $\sigma_{\text {II }}$ are removed based on the softening behavior obtained from experimental bridging principles. Therefore, for the separation values $\left(\delta_{\mathrm{II}}\right)$ larger than $\delta_{1, \mathrm{II}}$, stresses are obtained from following equation.

$$
\begin{gathered}
\sigma_{I I}\left(\delta_{I I}\right)=2 A\left(\delta_{I I}-\delta_{1, I I}\right) \delta_{I I}+B \\
\delta_{C, I I}=\delta_{1, I I}+\delta_{C, I I}{ }^{*}
\end{gathered}
$$


When $\delta_{\text {II }}$ is larger than $\delta_{\mathrm{c}, \mathrm{II}}$, the bridging fibers lose their load bearing capacity and yield. Therefore, stresses are eliminated. By placing $\mathrm{G}_{\mathrm{II}, 0}$ in the proposed traction-separation equation, the total consumption of energy at the end of FPZ becomes equal to the desired amount of ERR, which is equal to the steady-state fracture toughness of $\mathrm{G}_{\mathrm{II}, \mathrm{SS}}$ and expressed with the surface area under the $\sigma_{\text {III- }} \delta_{\text {II }}$ curve (Fig. 18).

$$
\begin{gathered}
G_{I I, S S}=\frac{1}{2} \sigma_{C, I I} \delta_{0, I I}+\sigma_{C, I I}\left(\delta_{1, I I}-\delta_{0, I I}\right)+\frac{1}{20} \sigma_{C, I I} \frac{\left(\delta_{1, I I}+\delta_{0, I I}\right)}{2}+\frac{1}{2} \sigma_{C, I I}\left(\delta_{C, I I}\right. \\
\left.\quad-\delta_{1, I I}\right)
\end{gathered}
$$

The parameters of the modified proposed traction-separation model (P2) used for the simulation of the ENF tests are presented in Table 5.

\begin{tabular}{|c|c|c|c|c|c|c|c|c|}
\hline \multicolumn{7}{|c|}{ Experimental parameters for P2- model } & \multirow{2}{*}{$\begin{array}{c}\text { Trapezoidal } \\
\text { model }\end{array}$} & \multirow{2}{*}{$\begin{array}{c}\begin{array}{c}\text { P2- } \\
\text { model }\end{array} \\
\delta_{1, I I} \\
(\mathrm{~mm})\end{array}$} \\
\hline & $\begin{array}{c}\mathrm{G}_{\mathrm{II}, 0} \\
(\mathrm{~N} / \mathrm{mm})\end{array}$ & $\begin{array}{c}\sigma_{C, I I} \\
(\mathrm{MPa})\end{array}$ & $\begin{array}{c}\delta_{0, I I} \\
(\mathrm{~mm})\end{array}$ & $\begin{array}{l}\delta_{C, I I}{ }^{*} \\
(\mathrm{~mm})\end{array}$ & $\begin{array}{c}\delta_{C, I I} \\
(\mathrm{~mm})\end{array}$ & $\begin{array}{c}\mathrm{G}_{\mathrm{II}, \mathrm{b}} \\
(\mathrm{N} / \mathrm{mm})\end{array}$ & & \\
\hline \multicolumn{9}{|c|}{ Code- 0} \\
\hline $\mathrm{CCM}$ & 0.24 & 19.78 & 1978E-6 & \multirow{2}{*}{$\begin{array}{l}0.105 \\
0.104\end{array}$} & \multirow{2}{*}{$\begin{array}{l}0.116 \\
0.115\end{array}$} & \multirow{2}{*}{$\begin{array}{l}1.05 \\
1.27\end{array}$} & 0.012 & 0.012 \\
\hline CBT & 0.29 & 23.81 & $2381 \mathrm{E}-6$ & & & & 0.012 & 0.012 \\
\hline CBBM & 0.78 & 49.4 & 494E-5 & 0.081 & 0.096 & 2.08 & 0.016 & 0.015 \\
\hline \multicolumn{9}{|c|}{ Code- 0.2} \\
\hline $\mathrm{CCM}$ & 0.48 & 32.45 & $3245 \mathrm{E}-6$ & 0.11 & 0.124 & 1.9 & 0.015 & 0.014 \\
\hline $\mathrm{CBT}$ & 0.33 & 21.46 & $2146 \mathrm{E}-6$ & 0.115 & 0.129 & 1.27 & 0.015 & 0.015 \\
\hline CBBM & 0.83 & 36.94 & $3694 \mathrm{E}-6$ & 0.108 & 0.129 & 2.1 & 0.023 & 0.022 \\
\hline \multicolumn{9}{|c|}{ Code- 0.43} \\
\hline $\mathrm{CCM}$ & 0.42 & 30.76 & $3076 \mathrm{E}-6$ & 0.131 & 0.144 & 2.1 & 0.014 & 0.013 \\
\hline $\mathrm{CBT}$ & 0.34 & 25.1 & $251 \mathrm{E}-5$ & 0.13 & 0.143 & 1.69 & 0.014 & 0.013 \\
\hline CBBM & 0.89 & 49.43 & 4943E-6 & 0.109 & 0.126 & 2.67 & 0.018 & 0.017 \\
\hline \multicolumn{9}{|c|}{ Code-1 } \\
\hline $\mathrm{CCM}$ & 0.34 & 28.43 & $2843 \mathrm{E}-6$ & 0.118 & 0.129 & 1.7 & 0.012 & 0.012 \\
\hline $\mathrm{CBT}$ & 0.33 & 26.85 & $2685 \mathrm{E}-6$ & 0.118 & 0.129 & 1.6 & 0.012 & 0.012 \\
\hline CBBM & 0.77 & 53.08 & 5308E-6 & 0.086 & 0.100 & 2.31 & 0.015 & 0.014 \\
\hline \multicolumn{9}{|c|}{ Code-2.1 } \\
\hline $\mathrm{CCM}$ & 0.35 & 28.4 & 284E-5 & 0.098 & 0.109 & 1.4 & 0.012 & 0.012 \\
\hline $\mathrm{CBT}$ & 0.38 & 29.23 & 2923E-6 & 0.098 & 0.110 & 1.45 & 0.013 & 0.013 \\
\hline CBBM & 1 & 51.45 & $5145 \mathrm{E}-6$ & 0.092 & 0.110 & 2.38 & 0.020 & 0.019 \\
\hline \multicolumn{9}{|c|}{ Code-4.1 } \\
\hline $\mathrm{CCM}$ & 0.4 & 28.56 & 2856E-6 & 0.11 & 0.123 & 1.6 & 0.012 & 0.013 \\
\hline $\mathrm{CBT}$ & 0.36 & 25.16 & $2516 \mathrm{E}-6$ & 0.109 & 0.122 & 1.4 & 0.013 & 0.014 \\
\hline CBBM & 0.96 & 45.01 & $4501 \mathrm{E}-6$ & 0.102 & 0.122 & 2.3 & 0.020 & 0.021 \\
\hline
\end{tabular}

Table 5. Experimental parameters for traction-separation law for mode II. 
In general, values obtained from the CBBM method are larger than values obtained from CBT and ECM methods. In addition, values extracted with trapezoidal models and the modified proposed model (P2) has a good consistency.

\section{CONCLUSION}

In this work, the main objective was investigation of the effectiveness of nano particles content on the bridging and cohesive parameters in Nano-composites Mode I and II fracture. Processing of the experimental measurements include construction of the R-curves (ERR versus crack length), reconstruction of these curves in terms of the pre-crack tip opening or sliding displacement and calculation of the corresponding bridging laws through the J-integral approach. For the calculation of the ERR in Mode I fracture, three different data reduction schemes have been utilized (CBT, ECM and MCC). For the calculation of the ERR in Mode II fracture, three corresponding data reduction schemes have been utilized (CCM, CBT and CBBM). The experimental bridging laws for nano-composite samples were converted into Traction-Separation models applicable to user defined interface/cohesive finite elements. A modified trapezoidal Traction-Separation model is proposed that addresses both the developed cohesive and fiber bridging zone during Mode I or II delamination propagation.

It is apparent from the results that the maximum values of the ultimate stress $(312.7$ $\mathrm{MPa})$, failure strain $(0.033 \%)$, and Young modulus $(11.36 \mathrm{GPa})$ belong to the samples with the weight ratios of $0.43,1$, and $2.1 \%$, respectively. Alumina nanoparticles can effectively improve the mechanical performances of glass/epoxy composites. Given that the experimental results, adding $0.43 \mathrm{wt} \%$ nanoparticles to composite DCB samples gives rise to increase of $116 \%, 68 \%$ and $70 \%$ in $\mathrm{G}_{\mathrm{I}, 0}$ calculated by CBT, ECM and MCC respectively. By the same token, $72 \%$ increase in $\mathrm{G}_{\mathrm{I}, \mathrm{ss}}$ is measured by CBT, while this value for ECM and MCC is $110 \%$ and $48 \%$ according to the experimental observations. A glance at the information supplied for $\mathrm{G}_{\mathrm{I}, \mathrm{b}}$ reveals that adding $43 \mathrm{wt} \%$ of nanoparticles leads to maximum $88 \%$ which calculated by ECM data reduction method.

Generally, in CBT method, adding nanoparticles to the composite samples up to $0.43 \%$ results in increase of critical stress compared with reference sample (Code - 0), while adding $1 \mathrm{wt} \%$ nanoparticles experiences a $25 \%$ decrease and in a completely different manner this value soars to $50 \%$ by adding $2.1 \mathrm{wt} \%$. The critical stress values in mode I derived by ECM method fluctuated somewhere between just below $0.04 \mathrm{MPa}$ and somewhere in the vicinity of $0.14 \mathrm{MPa}$ belonging to the sample with $1 \mathrm{wt} \%$ nanoalumina particles. In stark contrast, though, the critical opening displacement for Code- 1 sample is the lowest value in comparison with those of the other samples in a low as $5 \mathrm{~mm}$, whereas this parameter for reference sample is $20 \mathrm{~mm}$. In MCC method, the highest critical stress belongs to the sample with $0.2 \mathrm{wt} \%$ at somewhere just below $0.08 \mathrm{MPa}$, while the maximum value for the critical displacement is calculated for Code- $4.1,42 \%$ higher than the reference sample. It is evident from the experimental data that adding $0.2 \mathrm{wt} \%$ nanoparticles to the composite samples results in $64 \%$ increase in critical stress in mode II fracture calculated by method CCM, this value for CBT and CBBM methods show an increase about just $8 \%$ and as high as $86 \%$ respectively. Adding more particles have no significant change in this feature. The sample Code- 0.43 has brought the highest value for 
sliding displacement measured by this method and that of CBT approach. The highest amount of critical stress has been appeared in CBBM method (about $50 \mathrm{MPa}$ ), while this method presented the lowest value for critical displacement, fluctuated between 0.08-.11 $\mathrm{mm}$ in mode II. There is not a good compliance between derived experimental results by CBBM method and those of the other two schemes.

\section{FUTURE WORK}

In the future work these experimental results for effect of Nano-particles on T-S parameters and bridging law in mode I and II fracture will be compared whit FEM results as experimental results would be used in FE software (ABAQUS).

\section{REFERENCES}

[1] ISO 15024:2001, Fibre-reinforced plastic composites: determination of mode I interlaminar fracture toughness, $\mathrm{G}_{\mathrm{IC}}$, for unidirectionally reinforced materials. 2008.

[2] ASTM D5528-01, Standard test method for Mode I interlaminar fracture toughness of unidirectional fiber-reinforced polymer matrix composites: In annual book of ASTM standards. 2007;15.

[3] ASTM D7905 / D7905M, Standard test method for determination of the mode ii interlaminar fracture toughness of unidirectional fiber-reinforced polymer matrix composites. 2014.

[4] Bensattalah T, Daouadji TH, Zidour M, Tounsi A, Bedia AA. investigation of thermal and chirality effects on vibration of single-walled carbon nanotubes embedded in a polymeric matrix using nonlocal elasticity theories. Mechanics of Composite Materials. 2016;52(4):555-568.

[5] Xu M, Wang BL, Yu A. Effect of surface and interface energies on the nonlinear bending behaviour of nanoscale laminated thin plates. Mechanics of Composite Materials. 2016;52 673-702.

[6] Chafidz A, Rizal M, RM F, Kaavessina M, Hartanto D, AlZahrani SM. Processing and properties of high density polyethylene/date palm fiber composites prepared by a laboratory mixing extruder. Journal of Mechanical Engineering and Sciences. 2018;12(3): 3771 - 3785.

[7] Zare Y. The roles of nanoparticles accumulation and interphase properties in properties of polymer particulate nanocomposites by a multi-step methodology. Composites Part A: Applied Science and Manufacturing. 2016;91:127-132.

[8] Liang X, Yang Y, Lou J, Sheldon BW. The impact of core-shell nanotube structures on fracture in ceramic nanocomposites. Acta Materialia. 2017;122:82-91.

[9] Chaeichian S, Wood-Adams PM, Hoa SV. Effect of morphology on fracture toughness of unsaturated polyester-based hybrid nanocomposites. Polymer. 2015, 72: $154-164$. 
[10] Shadlou S, Alishahi E, Ayatollahi MR. Fracture behavior of epoxy nanocomposites reinforced with different carbon nano-reinforcements. Composite Structures. 2013;95:577-581.

[11] Vanpariya M, Desai C, Patel H, Babariya D. Determination of Traction Separation Curve for Copper Using Essential Work of Fracture (EWF) Approach. Materials today: proceedings. 2018, 5(9):17162-17169.

[12] Rajan S, Sutton MA, Fuerte R, Kidane A. Traction-separation relationship for polymer-modified bitumen under mode I loading: double cantilever beam experiment with stereo digital image correlation. Engineering Fracture Mechanics. 2018; 187: 404-421.

]13] Park K, Choi H, Paulino GH. Assessment of cohesive traction-separation relationships in ABAQUS: A comparative study. Mechanics Research Communications. 2016; 78: 71-78.

[14] Ghabezi P, Farahani M, Fakhr M. Experimental investigation of nano-alumina effect on the filling time in VARTM process. Journal of Fundamental and Applied Sciences. 2016; 8(2): 925-940.

[15] Ghabezi P , Farahani M, Hosseini fakhr M, Abroshan H. Investigation of Mechanical Behavior of Alfa and Gamma Nano- Alumina/ Epoxy Composite Made By VARTM. International Journal of Advanced Biotechnology and Research. 2016; 7(3):731-736.

[16] Ghabezi P, Farahani M. Composite adhesive-bonded joint reinforcement by incorporation of nano-alumina particles. Journal of Computational Applied Mechanic. 2016;47(2):231-239.

[17] Khoran M, Ghabezi P, Frahani MR, Besharati MK. Investigation of drilling composite sandwich structures. The International Journal of Advanced Manufacturing Technology. 2014;76:9-12.

[18] Ghabezi P, Golzar M. Investigation and modeling of compaction behavior of plain fabrics. Applied Mechanics and Materials. 2012;110-116:611-615.

[19] Ghabezi P, Golzar M, Corrugated composite skins, Journal of Mechanics of Composite Materials. 2014;50(2):199-212.

[20] Ghabezi P, Farahani M. Trapezoidal traction-separation laws in mode II fracture in nano-composite and nano-adhesive joints. Journal of Reinforced Plastics and Composites. 2018;37(11): 780-794.

[21] Anyfantis KN, Tsouvalis NG. A novel traction-separation law for the prediction ofthe mixed mode response of ductile adhesive joints. International Journal of Solids and Structures. 2012;49:213-226.

[22] Ghabezi P, Farahani M, Experimental investigation of nanoparticles effects on cohesive model and bridging laws of mode I fracture in the adhesive joints. Journal of Adhesion Science and Technology. 2017;31(16):1807-1823.

[23] Heidarpour F, Farahani M, Ghabezi P. Experimental investigation of the effects of adhesive defects on the single lap joint strength. International journal of adhesion and adhesives. 2018; 80:128-132. 
[24] Kanninen, MF, Popelar, CH. Advanced fracture mechanics. Oxford University Press, Oxford. 1985.

[25] Wang Y, Williams JG. Corrections for mode II fracture toughness specimens of composite materials. Composites Science and Technology. 1992;43:251-256.

[26] De Moura MFSF, Campilho RDSG, Gonçalves JPM. Pure mode II fracture characterization of composite bonded joints. International Journal of Solids and Structures. 2009;46:1589-1595. 